\title{
Chapter 6 \\ Treatment of Wastewater with High \\ Proportion of Industrial Wastewater \\ with Extreme Requirements \\ on the Elimination of Nutrients
}

Max Dohmann, Yunbo Yun, and Vivien Lee

\subsection{Introduction}

China's industrial and economic development over the past 20 years has particularly affected the provinces on the east coast of China. The absolute focus of development has been the Greater Shanghai region and the Yangtze delta area. This development was accompanied by a high demand for drinking water and industrial water and a correspondingly high volume of wastewater. The inadequate treatment of wastewater from municipalities, industry and agriculture led to a significant deterioration in the quality of water resources. This applies in particular to Lake Tai, the most important regional water resource in the greater Shanghai area. In the summer of 2007, Lake Tai developed very strong eutrophication for the first time, so that the water could no longer be used for drinking water supply for a time. Due to the massive expansion of wastewater treatment with nutrient elimination that has taken place in the meantime, the conditions have improved somewhat.

With the 13th Five-Year Plan of the Chinese government, water protection has gained special political significance since 2016. This included much stricter targets for the water quality of sensitive waters such as Lake Tai. As a result, Jiangsu Province, to which a large part of the lake catchment area belongs, issued new requirements for wastewater treatment. These are specified in the "Discharge Standard of Main Wastewater Pollutants for Municipal Wastewater Treatment Plant \& Key Industries of Taihu Lake Area". This also applies to the nutrient elimination requirements for the treatment plants in the lake catchment area. Previously, two categories of wastewater treatment plants were considered: Category I wastewater treatment plants with less than 50\% industrial wastewater and Category II wastewater treatment plants with more than 50\% industrial wastewater. Since May 2018,

M. Dohmann $(\varangle) \cdot$ Y. Yun · V. Lee

Research Institute for Water and Waste Management, RWTH Aachen University (FiW) e. V., Aachen, Germany

e-mail: dohmann@fiw.rwth-aachen.de 
new requirements have been in effect, which were published in DB32/1072-2018. These apply to all wastewater treatment plants regardless of the respective industrial wastewater content. Limit values for the nutrient parameters nitrogen and phosphorus play a special role. A comparison of the limit values of the guidelines for the Tai Lake catchment area and the original quality specification according to the Chinese Water Protection Directive GB18918-2002 (I-A) was made in Table 6.1. It can be seen that above all the stricter requirements for nitrogen elimination, which have been tightened since 2018, represent a particular challenge for wastewater treatment plants.

A comparison of the minimum requirements applicable in Germany for the effluent quality of municipal wastewater treatment plants of different size classes and Chinese requirements is shown in Table 6.2. It should be noted, however, that

Table 6.1 Requirements for wastewater treatment plant discharges in the Tai Lake area according to Guidelines DB32/1072-2007 and DB32/1072/2018 and process standard I-A according to Chinese Water Protection Directive GB18918-2002

\begin{tabular}{|c|c|c|c|c|c|c|c|}
\hline \multirow{3}{*}{\multicolumn{2}{|c|}{ Parameter }} & \multicolumn{3}{|c|}{ DB32/1072-2007 } & \multicolumn{2}{|c|}{ DB32/1072-2018 } & \multirow{3}{*}{$\begin{array}{c}\text { GB18918-2002 } \\
\text { SK I-A }\end{array}$} \\
\hline & & \multicolumn{2}{|c|}{$\begin{array}{c}\text { until } \\
12 / 31 / 2007\end{array}$} & \multirow{3}{*}{$\begin{array}{c}\text { since } \\
01 / 01 / 2008 \\
50 \\
\end{array}$} & \multirow{3}{*}{$\begin{array}{c}\begin{array}{c}\text { since } \\
06 / 01 / 2018\end{array} \\
50 \\
\end{array}$} & \multirow{3}{*}{$\begin{array}{c}\text { from the } \\
01 / 01 / 2021 \\
40\end{array}$} & \\
\hline & & I & $\|$ & & & & \\
\hline COD & {$[\mathrm{mg} / \mathrm{l}]$} & 50 & 60 & & & & 50 \\
\hline $\mathrm{NH}_{4}-\mathrm{N}$ & {$[\mathrm{mg} / \mathrm{l}]$} & $5(8)^{*}$ & $5(8)^{*}$ & $5(8)^{*}$ & $4(6)^{*}$ & $3(5)^{*}$ & $5(8)^{*}$ \\
\hline TN & {$[\mathrm{mg} / \mathrm{l}]$} & 20 & 15 & 15 & $12(15)^{*}$ & $10(12)^{*}$ & 15 \\
\hline TP & {$[\mathrm{mg} / \mathrm{l}]$} & 0,5 & 0,5 & 0,5 & 0,5 & 0,3 & 0,5 \\
\hline \multicolumn{8}{|c|}{${ }^{*}$ for temperatures $\leq 12^{\circ} \mathrm{C}$} \\
\hline
\end{tabular}

Table 6.2 Comparison of German minimum requirements for wastewater treatment plant effluents according to the Waste Water Ordinance (ABWV 2004) and Chinese requirements (see also Table $6.1)$

\begin{tabular}{|c|c|c|c|c|c|c|c|c|}
\hline \multicolumn{2}{|c|}{ Parameter } & \multicolumn{5}{|c|}{ Size class } & SK I-A & DB32- \\
$\mathbf{2}$ & $\mathbf{1}$ & $\mathbf{2}$ & $\mathbf{3}$ & $\mathbf{4}$ & $\mathbf{5}$ & & $\mathbf{2 0 1 8}$ \\
\hline $\begin{array}{c}\text { Größen- } \\
\text { klasse }\end{array}$ & $\begin{array}{c}(\mathrm{kg} / \mathrm{d} \\
\mathrm{BOD})\end{array}$ & $<60$ & $60-300$ & $300-600$ & $600-6.000$ & $>6000$ & - & - \\
\hline $\mathrm{COD}$ & {$[\mathrm{mg} / \mathrm{l}]$} & 150 & 110 & 90 & 90 & 75 & 50 & 50 \\
\hline $\mathrm{BOD}$ & {$[\mathrm{mg} / \mathrm{l}]$} & 40 & 25 & 20 & 20 & 15 & 10 & - \\
\hline $\mathrm{NH}_{4}-\mathrm{N}$ & {$[\mathrm{mg} / \mathrm{l}]$} & - & - & 10 & 10 & 10 & 5 & 4 \\
\hline $\mathrm{TN}$ & {$[\mathrm{mg} / \mathrm{l}]$} & - & - & - & 18 & 13 & 15 & 12 \\
\hline $\mathrm{TP}$ & {$[\mathrm{mg} / \mathrm{l}]$} & - & - & - & 2 & 1 & 0,5 & 0,5 \\
\hline
\end{tabular}


the German minimum requirements in Table 6.2 are based on an emissions analysis only. Higher requirements may result in Germany from emission aspects. Nevertheless, the comparison in Table 6.2 shows the particularly high Chinese requirements for nitrogen elimination in the Tai Lake area that have been in force since 2018.

The background to the investigations described in this report was provided at the beginning of 2016 by contacts between German researchers within the framework of the Chinese Major Water Programme and the Chinese company Huayan Water Affairs Co., Ltd., which is responsible for water supply and wastewater disposal in the Suzhou Industrial Park on Lake Tai. Discussions held with the regional water authorities during this period revealed that in future, extreme demands will be placed above all on nitrogen elimination at the Tai Lake treatment plants. The talk was of a discharge value for total nitrogen of less than $6 \mathrm{mg} / \mathrm{L}$. The discussed effluent value for the COD should be $30 \mathrm{mg} / \mathrm{L}$. This resulted in a German-Chinese research project with the aim of investigating technical possibilities to meet such extreme requirements. The research project was carried out with the participation of the Research Institute for Water and Waste Management at the RWTH Aachen University (FiW) and the companies Atemis $\mathrm{GmbH}$, Aachen and EvU GmbH, Gröditz on the German side and the University of Shanghai for Science and Technology and the company Huayan Water Affairs Co. The German Ministry of Education and Research (BMBF) provided funding for the German research work carried out in this project as part of the German-Chinese Major Water Cooperation.

\subsection{Industrial Wastewater Treatment in China}

For the year 2015, the share of industrial wastewater in China was stated as $26.2 \%$ of total wastewater (Xiang 2017). Most industrial wastewater in China is discharged into municipal sewerage systems or sewage treatment plants. However, it can be assumed that the actual share of industrial wastewater is higher. Not all small and mediumsized industrial enterprises are included in the statistics. In 2015, industrial wastewater in China had a COD content of $25.8 \%$ and a NH4-N content of $13.9 \%$, compared to 74.9 and $86.1 \%$ of domestic wastewater respectively (Xiang 2017). However, even a certain increase in the industrial wastewater fraction would not adequately reflect the major environmental impacts caused compared to domestic wastewater. Many industrial effluents are contaminated with pollutants that are not adequately retained by treatment in sewage treatment plants and thus lead to disproportionate water pollution.

The following are the characteristics of industrial wastewater compared to domestic wastewater:

- one-sided composition of the wastewater constituents

- high concentration of individual wastewater constituents

- high fluctuations in the concentrations

- intermittent wastewater flow and $\mathrm{pH}$ fluctuations 
- elevated temperatures

- dyes or persistent organic substances.

A particular problem is the treatment of industrial wastewater with high organic loads that are not or only with difficulty biodegradable and the load of heavy metals. Up to now, compliance with specified concentrations in the effluent of many Chinese wastewater treatment plants has only been possible by diluting industrial wastewater with less or non-contaminated wastewater. The consequence must be that in the future highly contaminated partial streams of industrial wastewater must be specifically pre-treated before further treatment.

There are various possibilities for the joint or separate treatment of municipal and industrial wastewater. Figure 6.1 shows the four basic concepts for the arrangement of the treatment plants. All four concepts have been implemented in German wastewater practice. Concept A is certainly only suitable for very large industrial plants. This also applies to concept $\mathrm{D}$, where municipal wastewater can be used for improved treatment of industrial wastewater. In China, most of the industrial wastewater is co-treated in municipal wastewater treatment plants.

When industrial wastewater is discharged into a municipal sewage system, it must be ensured that the requirements for the effluent quality of the plants are met. Beyond the aspects of water protection, it must be ensured that the sewage system is not damaged by industrial wastewater. Structural damage can be expected, for example, if high sulphate or ammonium concentrations are present. In order to protect public sewage systems from such damage, appropriate concentration limits should therefore be observed.

For larger industrial plants with wastewater from different production processes, a material flow separation with correspondingly differentiated wastewater treatment has proven to be effective in Germany for water protection reasons. In this way, improved recycling of wastewater and wastewater constituents can be achieved. The amount of recycled and reused wastewater has so far remained low in China, with only
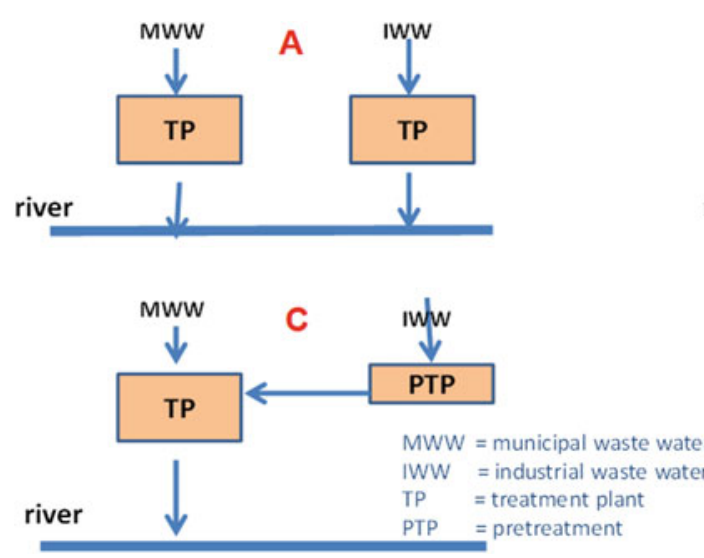
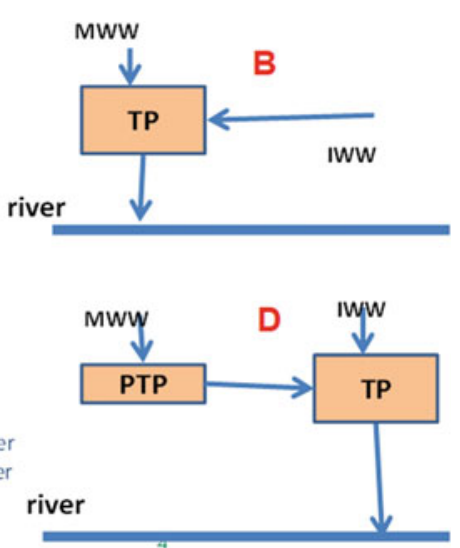

Fig. 6.1 Basic concepts for the treatment of municipal and industrial wastewater (Dohmann 2014) 
$10 \%$ of treated industrial wastewater (Xu 2016). In recent years, several guidelines for water recycling have been published in China (Xu 2016). For example, the Water Pollution Prevention Action Plan and Control Action Plan of April 2015 states that by 2020 the rate of use of recycled water should be $20 \%$ in water-poor cities and $30 \%$ in the Jing-Jin-Ji area, which is a particular challenge for planning new industrial wastewater systems in China and complementing existing ones.

\subsection{The Study Area and Investigated Wastewater Treatment Plant}

The study area, the Suzhou Industrial Park (SIP), covers part of the urban area of Suzhou to the west of Shanghai (see Fig. 6.2). In terms of water management, the region is characterized by Lake Tai, which serves as an important water resource for the metropolitan areas of Suzhou, Wuxi, Changzhou and Nanjing. The city of Suzhou is particularly well known for its numerous canals, which is why it was given the name "Venice of China". In recent decades, the economic output in Suzhou has grown very strongly with the settlement of many industrial companies. The Suzhou Industrial Park was founded in 1992 and covers a catchment area of $278 \mathrm{~km}^{2}$ with over 2,000 industrial companies.

Suzhou Industrial Park has two wastewater treatment plants of roughly the same size, which treat the industrial wastewater and domestic wastewater of the approximately 800,000 inhabitants living in the park's catchment area. The investigations carried out in the research project related to the Suzhou II WWTP, located in the southern part of the park. This plant, commissioned in 2010, was designed for a daily wastewater inflow of $150,000 \mathrm{~m}^{3}$. In 2017 , the average daily inflow was about $172,000 \mathrm{~m}^{3}$. The share of treated industrial waste water accounted for almost $60 \%$ of

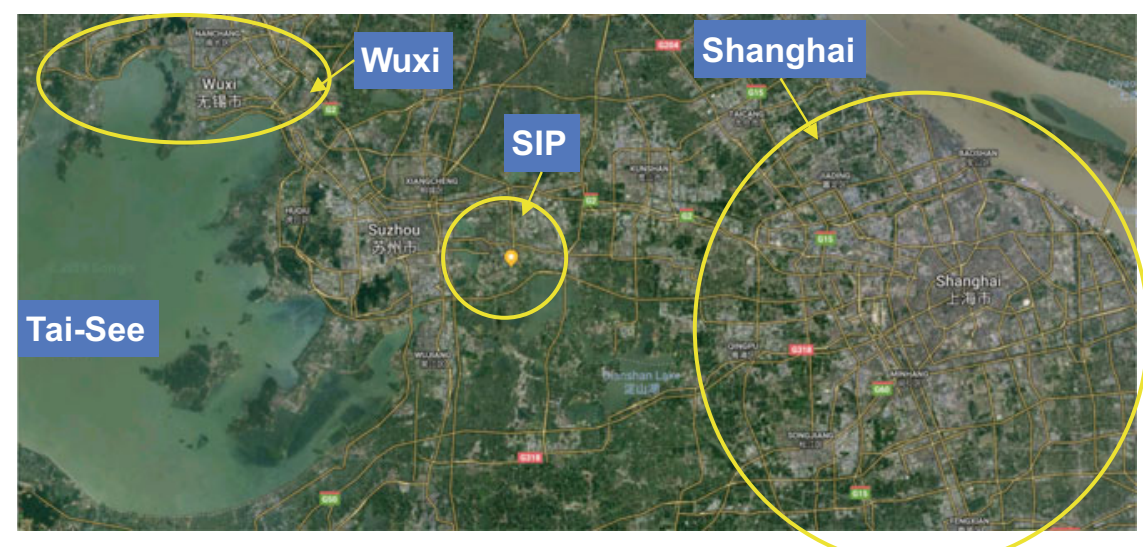

Fig. 6.2 Regional location of Suzhou Industrial Park (Google Maps 2018) 


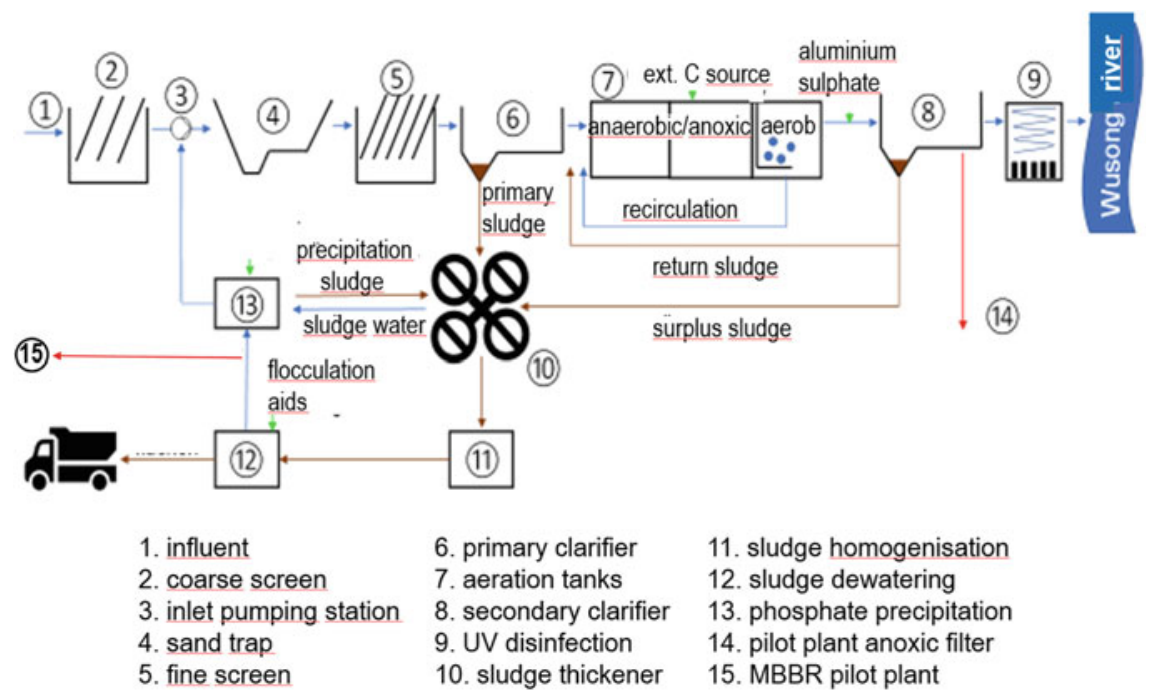

Fig. 6.3 Process diagram of the investigated Suzhou II wastewater treatment plant in the Suzhou Industrial Park (Lee 2018)

the total inflow. The basic concept of this wastewater treatment plant corresponds to the concept in Fig. 6.1C, although, unlike in Fig. 6.1, all sewers and the wastewater treatment plant are operated by the private company Huayan Water.

Figure 6.3 shows the process diagram of Suzhou II WWTP and the location of the two pilot plants, which are reported on in more detail in Chap. 6.3.2 and 6.3.3.

The treatment plant has a classical process engineering for municipal wastewater. In contrast to most Chinese wastewater treatment plants, a sedimentation stage takes place before the biological treatment according to the AAO system. The wastewater treatment plant is equipped with extensive online measuring technology. First of all, $\mathrm{pH}$ value, temperature, COD, NH4-N, TN and TP are measured behind the fine screen. In the aerobic part of the biological stage, the online values of $\mathrm{O} 2$, redox potential, solids content, TN and TP are measured, while at the UV disinfection stage $\mathrm{pH}$, temperature, COD, filterable substances, NH4-N, TN and TP are recorded. The phosphorus elimination is carried out biologically and by means of a simultaneous precipitation with aluminium sulphate.

The sludge produced in the sedimentation stage is thickened together with the excess sludge of the biological stage and dewatered mechanically with centrifuges with the addition of flocculation aids. The sludge is then dried in an external drying plant. The sludge dried to $90 \%$ dry substance is then incinerated in a thermal power plant. The process water from the thickeners and the mechanical sludge dewatering is treated in a precipitation plant before being returned to the inlet pumping station for phosphate elimination.

Table 6.3 shows the design values for the treatment plant and the mean inflow values in 2017 and in the investigation phase. During the investigations, the pollutant 
Table 6.3 Inflow values of the investigated Suzhou II wastewater treatment plant (Lee 2018)

\begin{tabular}{|c|c|c|c|c|}
\hline \multicolumn{2}{|c|}{ Parameter } & $\begin{array}{c}\text { planned } \\
\text { loads }\end{array}$ & $\begin{array}{c}\text { inflow values } \\
\mathbf{2 0 1 7}\end{array}$ & $\begin{array}{l}\text { average inflow values } \\
\text { in the project phase }\end{array}$ \\
\hline average inflow rate & {$\left[\mathrm{m}^{3 /} / \mathrm{d}\right]$} & 150.000 & 172.092 & 163.322 \\
\hline dry weather inflow & {$\left[\mathrm{m}^{3} / \mathrm{d}\right]$} & 130.000 & - & - \\
\hline maximum inflow & {$\left[\mathrm{m}^{3} / \mathrm{h}\right]$} & 8125 & - & - \\
\hline $\mathrm{BOD}$ & {$[\mathrm{mg} / \mathrm{l}]$} & $20-250$ & 232 & 288 \\
\hline $\mathrm{COD}$ & {$[\mathrm{mg} / \mathrm{l}]$} & 500 & 447 & 571 \\
\hline $\mathrm{TN}$ & {$[\mathrm{mg} / \mathrm{l}]$} & $15-55$ & 37 & 44 \\
\hline $\mathrm{NO}_{3}-\mathrm{N}$ & {$[\mathrm{mg} / \mathrm{l}]$} & & 3 & 2 \\
\hline $\mathrm{TP}$ & {$[\mathrm{mg} / \mathrm{l}]$} & $0,25-6$ & 5 & 7 \\
\hline filterable SS & {$[\mathrm{mg} / \mathrm{l}]$} & 350 & 194 & 202 \\
\hline
\end{tabular}

Table 6.4 Requirements for industrial wastewater when discharged into the sewerage system in Suzhou Industrial Park according to CJ343-2010

\begin{tabular}{|c|c|c|c|c|c|c|c|}
\hline $\begin{array}{c}\mathrm{COD} \\
{[\mathrm{mg} / \mathrm{l}]}\end{array}$ & $\begin{array}{c}\mathrm{BOD} \\
{[\mathrm{mg} / \mathrm{l}]}\end{array}$ & $\begin{array}{c}\text { filter.SS } \\
{[\mathrm{mg} / \mathrm{l}]}\end{array}$ & $\mathbf{p H}$ & $\begin{array}{c}\mathrm{NH}_{4}-\mathrm{N} \\
{[\mathrm{mg} / \mathrm{l}]}\end{array}$ & $\begin{array}{c}\mathrm{TN} \\
{[\mathrm{mg} / \mathrm{l}]}\end{array}$ & $\begin{array}{c}\mathrm{TP} \\
{[\mathrm{mg} / \mathrm{l}]}\end{array}$ & $\begin{array}{c}\text { Oil } \\
{[\mathrm{mg} / \mathrm{l}]}\end{array}$ \\
\hline$\leq 500$ & $\leq 350$ & $\leq 400$ & $6,7 \sim 9,5$ & $\leq 45$ & $\leq 70$ & $\leq 8$ & $\leq 20$ \\
\hline
\end{tabular}

load of the plant corresponded to an estimated 665.000 population equivalents. Due to the further expansion of industry and the planned further expansion of residential development in the industrial park, the Suzhou II wastewater treatment plant is to be expanded to a daily inflow load of $300.000 \mathrm{~m}^{3}$.

For the industrial wastewater generated in the Suzhou Industrial Park, requirements must be met before it is discharged into the sewerage system. According to the Chinese guideline CJ343-2010, these relate to the $\mathrm{pH}$ value, organic pollutants, nutrients and oil content. The corresponding limit values are shown in Table 6.4.

\subsection{Investigation Approaches}

The overall objective of the research project was to reduce the nutrient content of the effluent from the Suzhou II sewage treatment plant. The main focus was the elimination of nitrogen with a target concentration of 10 or even $6 \mathrm{mg} / \mathrm{L}$. In connection with the elimination of the organic effluent values, which also had to be improved, the investigations in Germany were to make use of the technological experience gained and German administrative management approaches. 


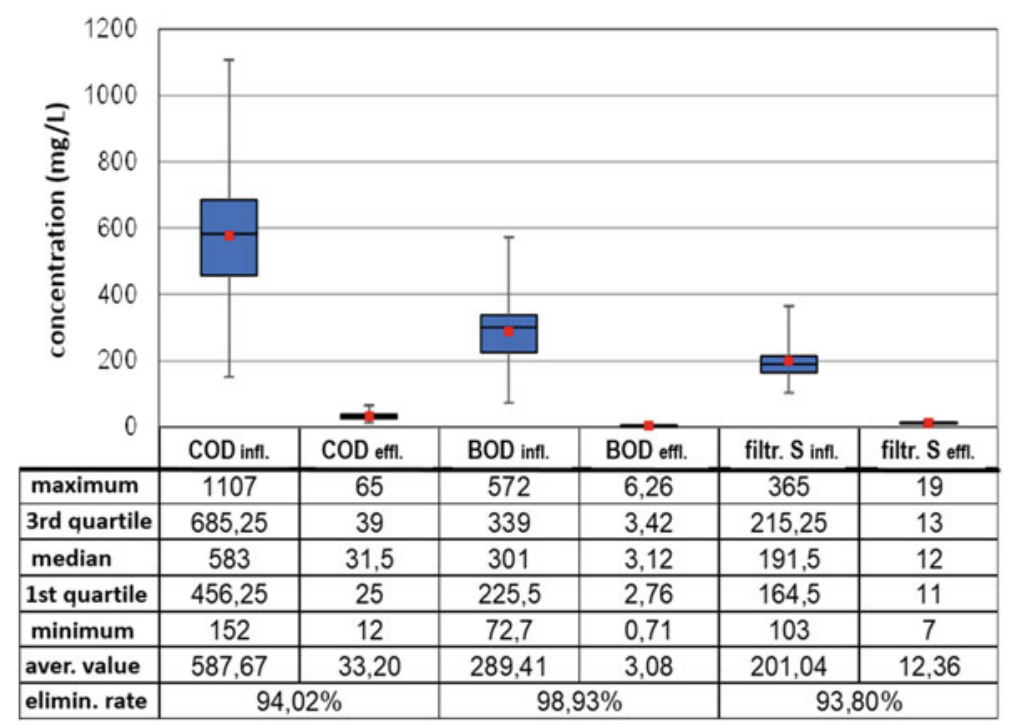

Fig. 6.4 Inflow and outflow values for the parameters COD, BOD and filtrateable substances for the Suzhou II wastewater treatment plant in the 2017/2018 investigation period (Lee 2018)

The necessity of further treatment effects for the Suzhou II wastewater treatment plant can be demonstrated by the previous inflow and outflow data of the plant. Figures 6.4 and 6.5 show the concentration ranges and elimination rates for the parameters COD, BOD5, filterable substances and the nutrient parameters nitrogen and phosphorus.

Figure 6.4 shows that although the mean COD effluent value of $31.5 \mathrm{mg} / \mathrm{L}$ was well below the requirements of $>50 \mathrm{mg} / \mathrm{L}$ applicable since 2008 , the maximum value measured was $65 \mathrm{mg} / \mathrm{L}$. If the future treatment capacities of the wastewater treatment plant are to ensure a maximum COD discharge value of $30 \mathrm{mg} / \mathrm{L}$, there is a need for a significantly improved COD elimination. Such a value of $30 \mathrm{mg} / \mathrm{L}$ could not be achieved by a solids-free effluent alone, but requires above all process engineering measures in the biological treatment stage.

Figure 6.5 illustrates the treatment performance of the Suzhou II WWTP for the nutrients nitrogen and phosphorus. In the case of phosphorus elimination, compliance with the requirement of $0.5 \mathrm{mg} / \mathrm{L}$ total phosphorus in the effluent, which is valid until 2021 (see Table 6.1), does not seem to pose a difficult problem. Even the effluent value $<0.3 \mathrm{mg} / \mathrm{L}$ applicable after 2021 appears to be well possible with an optimization of the previous elimination mechanisms. The maximum measured value of $1.03 \mathrm{mg} / \mathrm{L}$ mentioned in Fig. 6.5 should certainly be considered as the outlier value.

In the case of nitrogen elimination, on the other hand, the situation is different. In the case of a massive disturbance of nitrification caused by industrial wastewater, there was a short-term extremely high ammonium nitrogen concentration in the wastewater treatment plant effluent during the period under study. This is not 


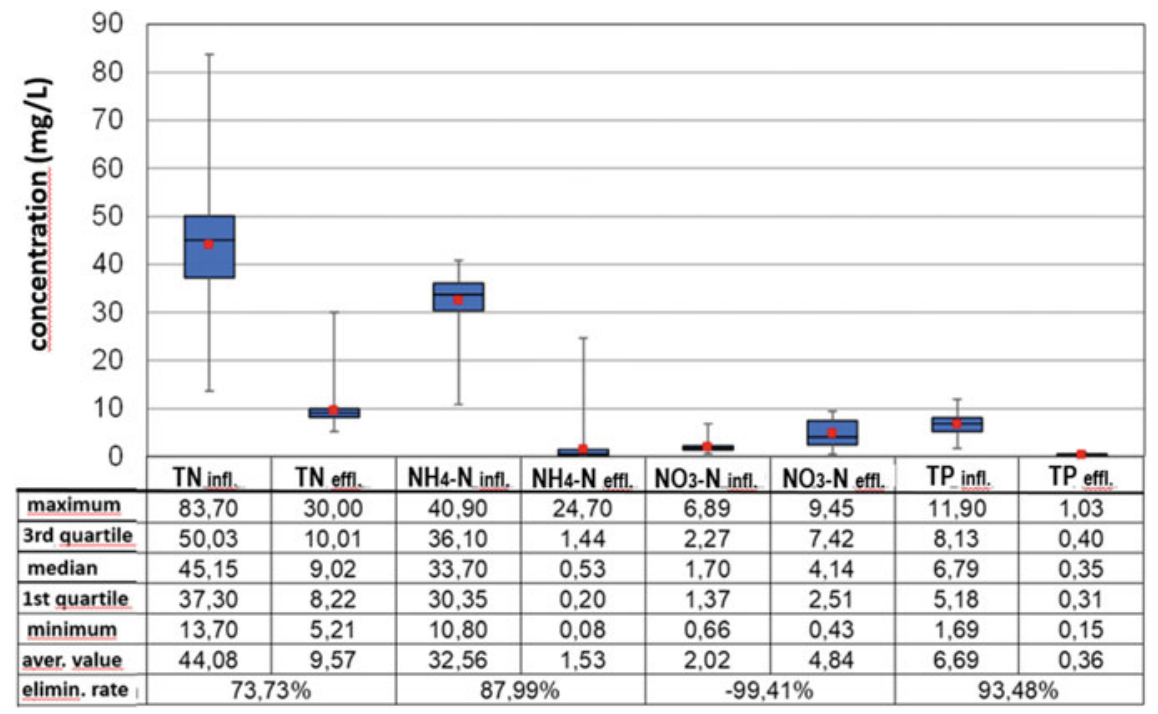

Fig. 6.5 Inflow and outflow values for the nutrient parameters total nitrogen(TN), Ammonium (NH4-N), nitrate (NO3-N), and total phosphorus (TP) for the Suzhou II wastewater treatment plant in the investigation period 2017/18 (Lee 2018)

unusual for industrial wastewater discharges, but given the size of this treatment plant, this represents a very significant water pollution, which should be avoided in the future by increased monitoring of indirect discharges. The total nitrogen value of the wastewater treatment plant effluent during the period of the above-mentioned disturbance was twice the concentration permitted until 2018.

As the mean value for total nitrogen was at the level of the requirement of $10 \mathrm{mg} / \mathrm{L}$ applicable from 2021 onwards according to Table 6.1, it is evident that about half of the measured values recorded were higher and that therefore a significantly improved nitrogen elimination is necessary in the future. This means a significant increase in the denitrification performance of the treatment plant. The discharge value for total nitrogen of $6 \mathrm{mg} / \mathrm{L}$ at most, which is the long-term objective, will probably be very difficult to meet in the long term at the nitrate levels shown in Fig. 6.5.

Based on the findings on the treatment performance of the Suzhou II WWTP and the requirements to be met in the future, the following work packages or investigation approaches were carried out within the framework of the research project:

a) Indirect discharger monitoring and management approaches with application of German experience for the recording and analysis of industrial wastewater discharges in the Suzhou Industrial Park

b) Investigations for the process engineering optimisation or completion of the existing Suzhou wastewater treatment plant

- optimisation of the operation mode of the primary clarification by laboratory tests to control the sedimentation, 
- C-dosage to increase denitrification in the biological stage by using German experience and laboratory experiments to test different substrates,

- Nitrogen elimination by downstream anoxic filtration - design, construction and operation of a pilot plant "denitrification filter",

- Nitrogen elimination from the partial flow of sludge water by conception, construction and operation of a SBR-MBBR test plant,

- Nitrogen elimination from the partial flow of sludge water through the design, construction and operation of a test plant for the deammonification.

The investigations were carried out in 2017 and 2018.

\subsection{Results of Investigation}

\subsubsection{Indirect Discharger Monitoring}

In Germany, the individual German provinces have issued regulations for the discharge of wastewater into public wastewater systems. The legal background for these so-called indirect discharger regulations is water protection. These ordinances refer to the German Wastewater Ordinance, which covers 57 source areas for wastewater (AbwV 2004). In addition to domestic wastewater, this concerns commercial and industrial wastewater from 56 different sectors. The indirect discharger regulations contain concentrations of various substances contained in the wastewater which must not be exceeded when it is discharged into a public sewerage system or a wastewater treatment plant. When determining these limit concentrations, it was taken into account that these constituents can be at least partially eliminated in wastewater treatment. The monitoring of industrial indirect dischargers in Germany is carried out by the local water authorities.

The German provinces oblige the operators of public wastewater treatment plants to keep a list of industrial enterprises whose waste water is expected to have a significant impact on the wastewater treatment plants or on water bodies. This register is known as the indirect discharger register and must be updated regularly. The establishments are obliged to provide the necessary information. The list shall be submitted to the competent water authority on request. There is decades of experience in Germany in the preparation of indirect discharger registers. The practical basis for this is a special set of rules (DWA 2013).

In addition to the requirements regulated by the water authorities for the discharge of industrial wastewater into public wastewater systems, requirements must also be set for the wastewater to be discharged in the interest of the operator. These requirements are intended to ensure that these discharges do not cause structural damage to the public wastewater systems and to guarantee the operational safety of the plants and the protection of the operating personnel. The corresponding requirements for the quality of wastewater are part of the respective municipal wastewater regulations. The operator of the public wastewater treatment plants is responsible for monitoring 
the industrial indirect dischargers with regard to these requirements. In Germany, therefore, parallel monitoring measures in the indirect discharge area are possible, but with different parameters, by the competent water authority and by the operator of the public wastewater facilities. For economic reasons, however, the monitoring is usually coordinated accordingly.

In China, the CJ 343-2010 discharge standard for indirectly discharged industrial wastewater has been in place for 10 years (see Table 6.4). This standard can be tightened regionally by the water authorities due to local boundary conditions. In practice, it has been found that operators often do not have sufficient information on industrial waste water and are not involved in monitoring discharges. This explains why Chinese municipal wastewater treatment plants are experiencing difficulties in meeting quality requirements.

The biggest challenge for the investigated Suzhou II wastewater treatment plant is the industrial wastewater to be treated. This is all the more true because in the future even more industrial plants will have to be connected to the treatment plant and significant production increases are expected from the plants with correspondingly higher wastewater loads. Therefore, for further operational optimisation of the treatment plant, it seems urgently necessary to establish a complete indirect discharger register in accordance with the German experience. At the moment there is only an incomplete directory. Although Huayan Water, the operator of the investigated wastewater treatment plant, is aware of the industrial enterprises connected to the treatment plant, it has no meaningful information on the fluctuations in the quality of the wastewater and the effects of in-house pretreatment.

It is strongly recommended that industrial wastewater discharges be monitored in consultation with the competent authorities. Based on German experience, the following strategy, which is useful for monitoring, should be used for this purpose:

- On-site monitoring of commercial and industrial indirect dischargers

- Monitoring of discharges at nodes in the sewer network

- Detection of illegal indirect discharges.

It is advisable to carry out online monitoring of the pre-treatment plants, at least for industrial plants with highly contaminated wastewater. In the event of disruptions in the operation of these plants and transmission of online data, measures such as commissioning emergency basins or dosing powdered activated carbon could be initiated at an early stage at the downstream wastewater treatment plant.

The monitoring of nodes in the sewer network is used to trace sporadic pollutant discharges. The regular taking of random samples or better of permanent mixed samples at selected sewer nodes is a useful supplement to the monitoring of indirect dischargers.

Different matrices can be used to detect unauthorized indirect discharges. Firstly, the information on the various industrial effluents discharged. However, an indirect determination can also be made about the nature of the biofilm on the sewer pipe walls or the sewer sediments. However, only pollutants that accumulate in solids are recorded. 


\subsubsection{Optimisation of the Existing Sedimentation Stage}

One approach to increase nitrogen elimination in existing wastewater treatment plants is the optimization of relevant treatment facilities. In the case of the Suzhou II wastewater treatment plant under investigation, it therefore seemed sensible to carry out investigations to improve the effect of sedimentation on denitrification in the plant. The main objective was to improve the $\mathrm{C} / \mathrm{N}$ ratio for nitrogen elimination in the biological stage.

In order to identify the sedimentation behaviour of the wastewater in the influent of the primary treatment plant more precisely and to demonstrate the sedimentation performance of the primary treatment plant, sedimentation tests were carried out in the treatment plant laboratory. To carry out the sedimentation tests, $5 \mathrm{~L}$ of wastewater were taken from the inflow of the sedimentation stage on 4 days at intervals of 2 days. Figure 6.6 shows the setup for the laboratory tests.

After reaching the respective sedimentation time (0/15/30/60/80 $\mathrm{min})$ a sample was taken from the respective vessel (Imhoff cone). The parameters COD (total and solved), BOD5, suspended solids, NH4-N and TN were then analysed for the five different samples.

The evaluation of the results of the sedimentation tests with regard to the suspended solids (SS) is shown in Table 6.5. It is shown that the concentration of SS decreased as expected over the $80 \mathrm{~min}$ period considered. The discernible fluctuations over time can be explained by the small number of measured values.

Table 6.5 shows that after $80 \mathrm{~min}$ of discontinuation a reduction of the suspended solids of around $26 \%$. This does not quite correspond to the reduction for municipal wastewater, but in view of the high proportion of industrial wastewater in wastewater treatment plant influent realistic.

A similar decrease of around $27 \%$ was observed for the COD, as shown in Table 6.6. However, the reduction of the COD did not result from the removal of the suspended COD fraction.

Table 6.6 also shows an $8 \%$ decrease in dissolved COD after a settling time of $80 \mathrm{~min}$. The BOD5 has not been analysed. However, it can be assumed that a greater reduction than for the COD has been achieved. This is assumed to be $33 \%$ for the carbon-nitrogen ratio.

No major effect on nitrogen values is to be expected from sedimentation. To show this also the laboratory tests performed. Table 6.7 shows the values for the total nitrogen is listed. This results in a decrease after 80 min settling time concentration of around $16 \%$.

For denitrification, the carbon/nitrogen ratio $(\mathrm{C} / \mathrm{N})$ in the biological treatment stage is of decisive importance. According to Tables 6.6 and 6.7, the inflow to primary treatment had an average COD/TN ratio of 11.45 . Since it is not the COD but the readily biochemically available carbon that is relevant for the assessment of this ratio, a BOD5/TN ratio of 6,7 can be determined in the sedimentation inflow, based on the mean values for BOD5 and TN according to Figs. 6.4 and 6.5. At reduction rates of 


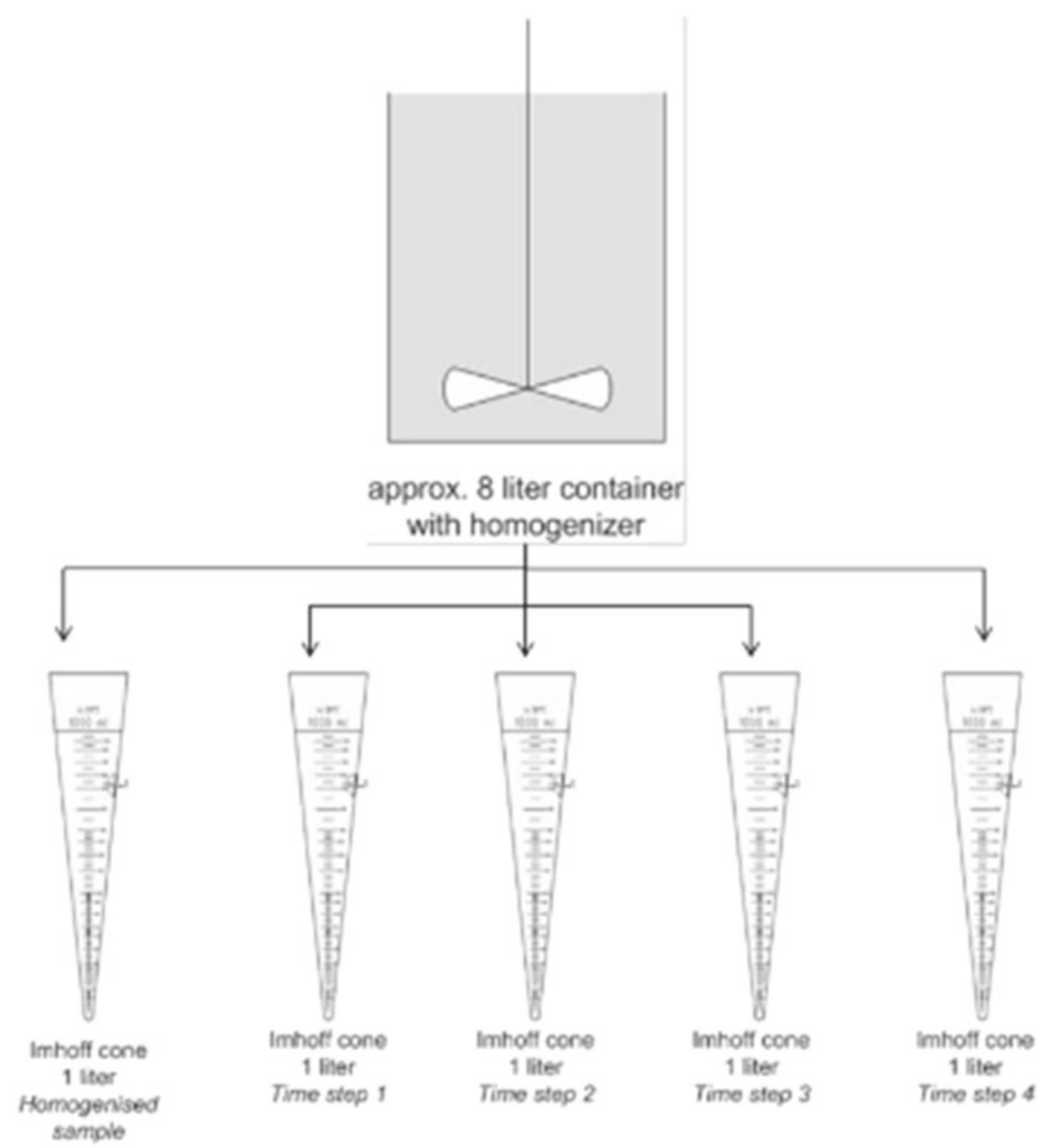

Fig. 6.6 Setup for laboratory investigations to optimize the sedimentation stage of investigated Suzhou II wastewater treatment plant

Table 6.5 Concentration of suspended solids at sedimentation investigations in the laboratory of the Suzhou II wastewater treatment plant

\begin{tabular}{|c|c|c|c|c|c|c|}
\hline & $\begin{array}{c}\text { settling time } \\
{[\mathrm{min}]}\end{array}$ & Minimum & Median & Maximum & $85 \%$-Quantile & Average \\
\hline \multirow{6}{*}{} & 0 & 105,0 & 128,5 & 185,0 & 179,0 & 139,8 \\
\cline { 2 - 7 } & 5 & 98,0 & 112,0 & 126,0 & 121,8 & 112,0 \\
\cline { 2 - 7 } & 10 & 85,0 & 103,0 & 121,0 & 115,6 & 103,0 \\
\cline { 2 - 7 } & 15 & 77,0 & 115,5 & 163,0 & 147,3 & 120,5 \\
\cline { 2 - 7 } & 25 & 75,0 & 88,5 & 102,0 & 98,0 & 88,5 \\
\cline { 2 - 7 } & 30 & 70,0 & 99,0 & 161,0 & 136,3 & 108,5 \\
\cline { 2 - 7 } & 60 & 80,0 & 123,5 & 163,0 & 137,8 & 120,7 \\
\cline { 2 - 7 } & 80 & 80,0 & 100,0 & 132,0 & 117,6 & 103,0 \\
\hline
\end{tabular}


Table 6.6 COD values for sedimentation tests in the laboratory of the Suzhou II wastewater treatment plant

\begin{tabular}{|c|c|c|c|c|c|c|}
\hline & $\begin{array}{c}\text { settling time } \\
{[\mathrm{min}]}\end{array}$ & Minimum & Median & Maximum & $85 \%$-Quantile & Average \\
\hline \multirow{4}{*}{ COD } & 0 & 320,0 & 425,0 & 544,0 & 475,0 & 419,3 \\
\cline { 2 - 7 } & 5 & 314,0 & 368,0 & 422,0 & 405,8 & 368,0 \\
\cline { 2 - 7 } & 10 & 304,0 & 355,0 & 406,0 & 390,7 & 355,0 \\
\cline { 2 - 7 } & 15 & 298,0 & 368,5 & 415,0 & 401,5 & 360,3 \\
\cline { 2 - 7 } & 25 & 296,0 & 332,5 & 369,0 & 358,1 & 332,5 \\
\cline { 2 - 7 } & 30 & 290,0 & 345,5 & 365,0 & 358,3 & 333,7 \\
\cline { 2 - 7 } & 60 & 292,0 & 308,0 & 348,0 & 337,2 & 314,0 \\
\hline \multirow{4}{*}{ COD $_{\text {solved }}$} & 80 & 283,0 & 301,0 & 344,0 & 325,6 & 307,3 \\
\cline { 2 - 7 } & 0 & 124,0 & 165,0 & 195,0 & 183,8 & 164,7 \\
\cline { 2 - 7 } & 5 & 158,0 & 165,5 & 173,0 & 170,8 & 165,5 \\
\cline { 2 - 7 } & 10 & 156,0 & 161,5 & 167,0 & 165,4 & 161,5 \\
\cline { 2 - 7 } & 25 & 121,0 & 155,0 & 181,0 & 169,0 & 155,0 \\
\cline { 2 - 7 } & 30 & 154,0 & 154,0 & 181,0 & 169,0 & 154,7 \\
\cline { 2 - 7 } & 60 & 118,0 & 154,5 & 183,0 & 165,0 & 153,0 \\
\hline & 80 & 137,0 & 155,0 & 181,0 & 171,1 & 157,0 \\
\hline
\end{tabular}

Table 6.7 Total nitrogen values in sedimentation tests in the laboratory of the Suzhou II wastewater treatment plant

\begin{tabular}{|c|c|c|c|c|c|c|}
\hline \multirow{7}{*}{$\begin{array}{c}\text { settling time } \\
{[\mathrm{min}]}\end{array}$} & Minimum & Median & Maximum & $85 \%$-Quantile & Average \\
\hline \multirow{6}{*}{$* \sqrt[4]{7}$} & 0 & 32,0 & 36,8 & 40,6 & 38,9 & 36,6 \\
\cline { 2 - 7 } & 5 & 34,6 & 36,9 & 39,2 & 38,5 & 36,9 \\
\cline { 2 - 7 } & 10 & 34,1 & 36,4 & 38,6 & 37,9 & 36,4 \\
\cline { 2 - 7 } & 15 & 31,2 & 34,6 & 38,7 & 37,8 & 35,1 \\
\cline { 2 - 7 } & 25 & 33,8 & 35,6 & 37,4 & 36,9 & 35,6 \\
\cline { 2 - 7 } & 30 & 29,7 & 33,9 & 36,0 & 36,0 & 33,8 \\
\cline { 2 - 7 } & 60 & 28,8 & 32,5 & 35,8 & 34,8 & 32,4 \\
\cline { 2 - 7 } & 80 & 26,9 & 29,7 & 36,1 & 33,5 & 30,6 \\
\hline
\end{tabular}

33 and $16 \%$ by sedimentation, respectively, this ratio would decrease to a 5.3 (Table 6.8 (Lee 2018)).

The above investigations of the sedimentation behaviour of the wastewater of the investigated wastewater treatment plant raise the question whether sedimentation before the biological stage should be avoided in the future. The existing sedimentation plant does have a number of advantages, such as the increased sludge age in the biological treatment stage and the use of the sludge produced in the primary sedimentation stage for energy generation in the existing digestion plant. However, the conditions for extensive denitrification deteriorate due to the reduced carbon/nitrogen ratio. The laboratory tests carried out have confirmed this.

There are several ways to reduce the negative effect of an existing sedimentation stage on denitrification. This can be done by reducing the settling time by taking a part of the tank volume out of operation. Another possibility is a partial bypass of the sedimentation, so that wastewater not settled with a partial flow is fed to the biological 
Table 6.8 C/N ratio during sedimentation tests in the laboratory of the Suzhou II wastewater treatment plant

\begin{tabular}{|c|c|c|}
\hline & $\begin{array}{c}\text { sett- } \\
\text { ling } \\
\text { time } \\
\text { [min] }\end{array}$ & Average \\
\hline \multirow{7}{*}{ An } & 0 & 11,5 \\
\cline { 2 - 3 } & 5 & 10,0 \\
\cline { 2 - 3 } & 10 & 9,8 \\
\cline { 2 - 3 } & 15 & 10,3 \\
\cline { 2 - 3 } & 25 & 9,3 \\
\cline { 2 - 3 } & 30 & 9,9 \\
\hline & 60 & 9,7 \\
\cline { 2 - 3 } & 80 & 10,0 \\
\hline
\end{tabular}

treatment stage. In view of the very extensive nitrogen elimination intended for the Suzhou II treatment plant, it does not appear advisable in any case to increase the sedimentation effect by increasing the volume or installing lamella separators.

\subsubsection{Optimisation of Nitrogen Elimination}

The significantly increased requirements for nitrogen elimination in wastewater treatment at Lake Tai means for the Suzhou II wastewater treatment plant opposite previous services a more extensive denitrification. This chapter will therefore on investigations carried out for various process engineering measures to improve the denitrification performance of the treatment plant.

\subsubsection{Optimizing the Dosage of External Carbon}

The heterotrophic microorganisms responsible for denitrification obtain the carbon and their energy from external organic sources. In contrast to the autotrophic nitrificants, they are not able to synthesize their energy from oxidation reactions themselves (Görner 1999). An optimal carbon/nitrogen ratio is between 12:1 and 15:1, but most of the municipal wastewater treatment plants in China have much lower ratios. These are usually between 6:1 and 8:1, which indicates an excess of nitrogen and limits denitrification. Very low total nitrogen contents cannot be achieved with this method. However, such conditions can be improved by adding an external carbon source.

The external carbon sources that can be used can be divided into conventional external, unconventional external and internal sources. In Germany, materials that can be assigned to these three groups have proven their worth in wastewater practice. 
Conventional carbon sources include substances such as methanol, ethanol, sugar beet syrup, acetic acid and technical salts. These offer different conditions. Thus, acetic acid is suitable for a rapidly effective support of denitrification, as the microorganisms require a very short adaptation time to the substrate. Methanol, on the other hand, is only converted by certain microorganisms, so that its effectiveness is lower.

In addition to conventional carbon sources, other carbon sources are increasingly gaining in popularity. These offer the advantage that they do not have to be produced separately, but are produced as waste or by-products in various industrial production processes and are usually much cheaper than conventional substrates. Examples of alternative external carbon sources include glycol-containing wastewater from chemical production, high-carbon wastewater from the beverage industry, breweries, the baking industry and ice cream production, and whey powder and crude glycerine from biodiesel production (Amed et al. 2000).

In addition to external carbon sources, there is also the possibility of using carboncontaining internal material flows in wastewater treatment plants to improve the denitrification capacity. For example, a targeted use of sewage sludge or sludge water is suitable for this purpose. A further possibility for activating carbon potential to improve denitrification is the comminution (disintegration) of the sewage sludge by mechanical or thermal means. An additional advantage of sewage sludge disintegration is the minimization of the sludge mass to be disposed of. A screenings washing also leads to an internal carbon source to be used and also reduces the disposal costs for the screenings.

Table 6.9 lists typical carbon sources for improving denitrification with their origin, advantages and disadvantages.

In the wastewater treatment at the Suzhou II wastewater treatment plant neither external carbon sources nor specific measures to use internal carbon potentials have been applied so far, since the requirements for nitrogen discharge values could be met even without such measures. Due to the need for more extensive nitrogen elimination in the future, a series of laboratory tests were carried out in the wastewater treatment plant laboratory in spring 2017 to determine the effect of a dosage of carbon on nitrogen elimination in the biological stage. Acetic acid and sodium acetate were added under anoxic conditions with different stirring times. Sodium actate is considered a preferred agent in China for improving the carbon/nitrogen ratio. Despite fluctuating results, the investigations can be described as successful.

However, for economic reasons and from the point of view of sustainability, in the long term the large-scale use of a carbon source derived from industrial residues should be aimed at. It may also be possible to use substances from industrial plants in the catchment area of the wastewater treatment plant. Once an indirect discharger register is available, the corresponding materials would have to be identified and examined in the laboratory for their suitability and effect before being used on an industrial scale. 
Table 6.9 Advantages and disadvantages of different external carbon sources to improve the denitrification of wastewater

\begin{tabular}{|c|c|c|}
\hline \multicolumn{3}{|c|}{ External carbon sources } \\
\hline & Advantages & Disadvantages \\
\hline Methanol & $\begin{array}{l}\text { - frequently used } \\
\text { - low cost } \\
\text { - low sludge accumulation }\end{array}$ & $\begin{array}{l}\text { - adaptation to biocenosis required } \\
\text { potential toxic effect }\end{array}$ \\
\hline Ethanol & $\begin{array}{l}\text { no adaptation to biocoenosis } \\
\text { required }\end{array}$ & $\begin{array}{l}\text { - higher sludge accumulation than } \\
\text { with methanol } \\
\text { - potential toxic effect } \\
\text { - higher.costs than methanol }\end{array}$ \\
\hline Acetate & $\begin{array}{l}\text { - no adaptation to biocoenosis: } \\
\text { required } \\
\text { - low sludge accumulation }\end{array}$ & $\begin{array}{l}\text { - high substrate demand } \\
\text { - higher costs than methanol } \\
\text { and ethanol }\end{array}$ \\
\hline \multicolumn{3}{|c|}{ Industrial residues } \\
\hline $\begin{array}{l}\text { Industrial } \\
\text { wastewater } \\
\text { z. B. brewery } \\
\text { wastewater }\end{array}$ & $\begin{array}{l}\text { - almost free } \\
\text { - desirable recycling product }\end{array}$ & $\begin{array}{l}\text { not constant condition } \\
\text { - quality control required } \\
\text { determine the amount } \\
\text { to be added }\end{array}$ \\
\hline \multicolumn{3}{|c|}{ Internal carbon sources } \\
\hline & Advantages & Disadvantages \\
\hline $\begin{array}{l}\text { acidified } \\
\text { sewage sludge, } \\
\text { sludge water }\end{array}$ & $\begin{array}{l}\text { - low cost } \\
\text { - no entry of foreign substances }\end{array}$ & $\begin{array}{l}\text { - possible additional N-entry } \\
\text { - not constant condition }\end{array}$ \\
\hline
\end{tabular}

\subsubsection{Use of a Downstream Anoxic Filter}

A possible technical solution for further nitrogen removal is the use of denitrification after the biological treatment stage. For this purpose an anoxic filter system is the best choice. At the Suzhou II wastewater treatment plant, a pilot plant designed and built in Germany was used for investigations. Figure 6.7 shows the test room with the pilot plant. The test facilities were housed in the container used to transport the plant from Germany to China.

Figure 6.8 shows a schematic diagram of the test facility with all its individual parts. The filter material used was an expanded clay material with a grain size of 4 to $8 \mathrm{~mm}$ and a quantity of $90 \mathrm{~L}$, which has proven itself in Germany for filtration. The carbon dosage was carried out using sodium acetate solutions ( $\mathrm{CH} 3 \mathrm{COONa})$ prepared in the laboratory. To assess the elimination performance of the pilot plant at 


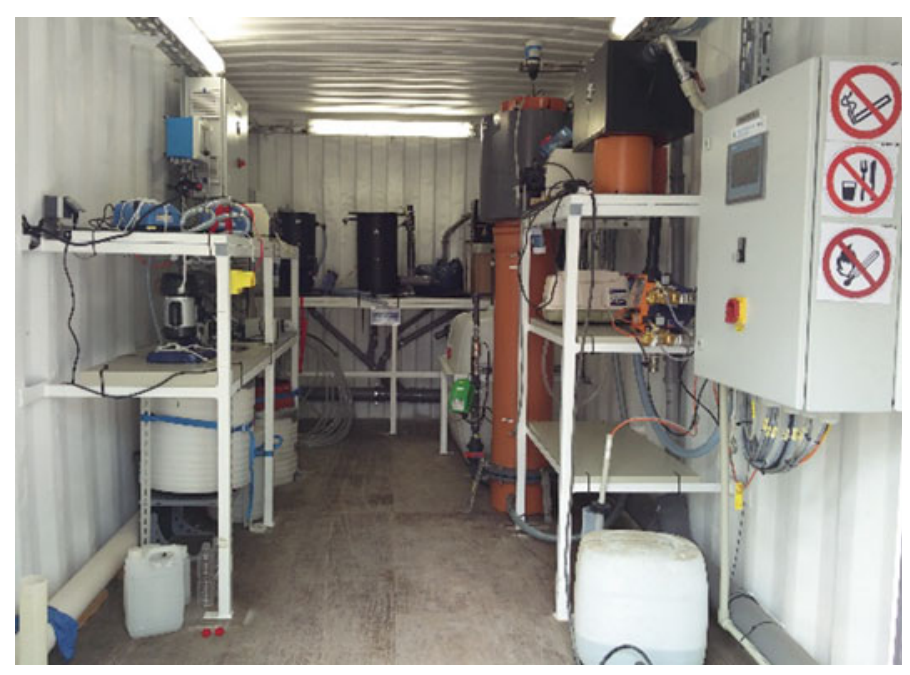

Fig. 6.7 Test room with the anoxic pilot filter system for the downstream denitrification at the Suzhou II wastewater treatment plant

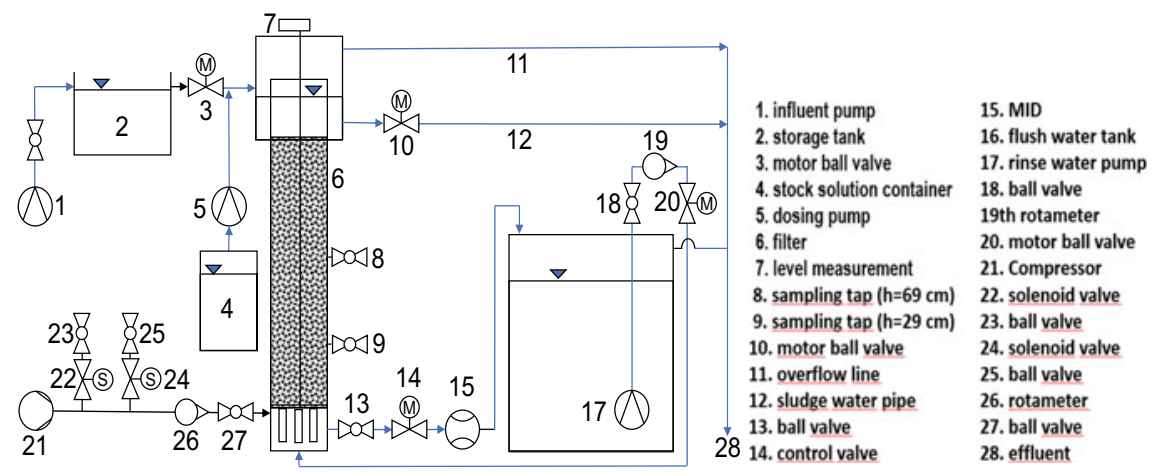

Fig. 6.8 Diagram of the pilot filter plant for denitrification

higher nutrient loads, an increase of nitrate in the filter influent in the form of sodium nitrate (NaNO3) was carried out in individual test sections.

The pilot tests carried out concerned the following parameter ranges:

- Nitrate addition with NaNO3 (max. $30 \mathrm{mg} / \mathrm{l} \mathrm{NO3-N),}$

- C:N ratio by carbon addition with $\mathrm{CH} 3 \mathrm{COONa}$ (max. COD:TN $=5: 1$ ),

- Flow rates between 30 and 110 [1/h]

With a multiparameter probe the parameters $\mathrm{pH}$, redox potential, oxygen content, conductivity, dissolved solids and temperature could be measured. In the la-bor of the wastewater treatment plant the parameters COD, TN, nitrate, nitrite, NH4-N and 
TP were analysed. The BOD5 was analysed provisionally. The analytical methods were carried out according to the Chinese standards.

Table 6.10 gives an overview of the technical data of the pilot filter plant and the feed data.

The COD and nitrogen values recorded during the investigation period in the effluent of the final clarification and in the filter inlet are shown in Fig. 6.9.

During the test period, there were significant fluctuations in the characteristics of the pilot plant influent, as shown in Fig. 6.9. This was particularly true in May 2018 , when a very pronounced disturbance of the operation of the treatment plant apparently occurred. The effluent values of the secondary clarification increased to a multiple of the previous values both for the COD and for the total nitrogen. It is remarkable that in spring 2018 the major part of the oxidised nitrogen in the effluent of the biological clarification stage was present as nitrite nitrogen and during the

Table 6.10 Technical data for the operation of the pilot filter plant for denitrification

\begin{tabular}{|c|c|c|c|c|c|}
\hline Feed flow & 30 & 60 & 90 & 110 & {$[/ / h]$} \\
\hline Flow time & 122,1 & 61,0 & 40,7 & 33,3 & [min] \\
\hline Filter velocity & 1,12 & 2,25 & 3,37 & 4,12 & {$[\mathrm{~m} / \mathrm{h}]\left[\mathrm{m}^{3} /\left(\mathrm{m}^{2} \cdot \mathrm{h}\right)\right]$} \\
\hline Filter material & \multicolumn{4}{|c|}{ Liaperl G 4-8 mm } & {$[-]$} \\
\hline Filter bed height & \multicolumn{4}{|c|}{1,25} & {$[\mathrm{~m}]$} \\
\hline Filter surface & \multicolumn{4}{|c|}{50,42} & {$\left[\mathrm{~m}^{2}\right]$} \\
\hline Effective reactor volume & \multicolumn{4}{|c|}{0,056} & {$\left[\mathrm{~m}^{3}\right]$} \\
\hline Filter bed volume & \multicolumn{4}{|c|}{0,09} & {$\left[\mathrm{~m}^{3}\right]$} \\
\hline Filter material bulk density & \multicolumn{4}{|c|}{717} & {$\left[\mathrm{~kg} / \mathrm{m}^{3}\right]$} \\
\hline Surface of the filter material & \multicolumn{4}{|c|}{900} & {$\left[\mathrm{~m}^{2} / \mathrm{m}^{3}\right]$} \\
\hline
\end{tabular}

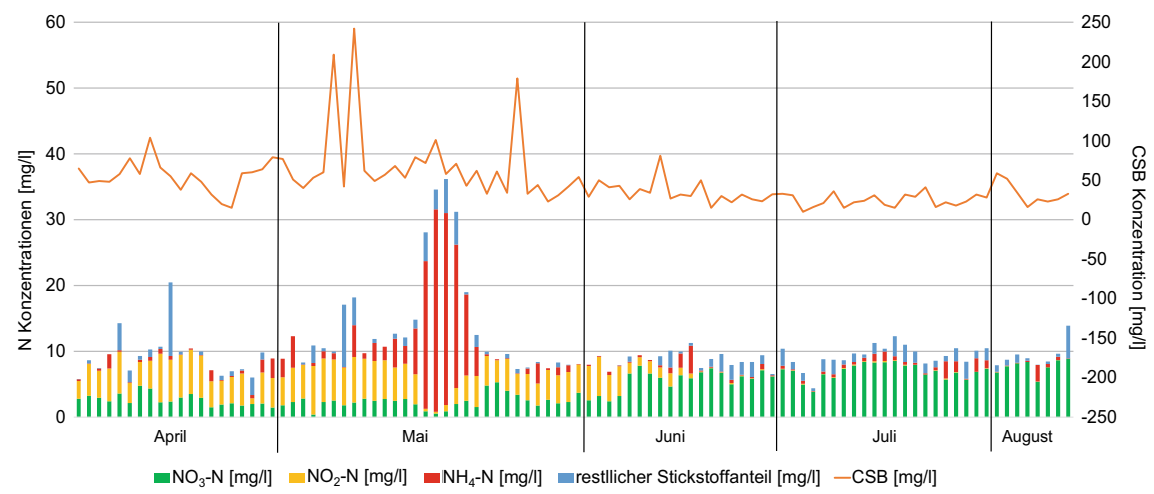

Fig. 6.9 COD and nitrogen values in the influent of the anoxic pilot filter in the test period 
Table 6.11 Average influent and effluent concentrations and elimination efficiency of the pilot filter for different parameters during a test series without addition of external carbon

\begin{tabular}{|c|c|c|c|c|c|c|c|}
\hline Parameter & $\mathrm{n}=18$ & $\mathrm{COD}$ & $\mathrm{TN}$ & $\mathrm{NO}_{3}-\mathrm{N}$ & $\mathrm{NO}_{2}-\mathrm{N}$ & $\mathrm{NH}_{4}-\mathrm{N}$ & $\mathrm{TP}$ \\
\hline $\begin{array}{c}\text { Influent concentr. } \\
\text { (mg/L) }\end{array}$ & $\varnothing$ & 26,1 & 8,52 & 6,61 & 0,11 & 0,37 & 0,67 \\
\cline { 2 - 8 } & $\mathbf{s}$ & 9,5 & 1,56 & 1,19 & 0,04 & 0,28 & 0,19 \\
\hline \multirow{2}{*}{$\begin{array}{c}\text { Effluent concentr. } \\
\text { (mg/L) }\end{array}$} & $\varnothing$ & 19,67 & 7,3 & 5,99 & 0,2 & 0,6 & 0,33 \\
\cline { 2 - 8 } & $\mathbf{s}$ & 7,78 & 1,41 & 1,19 & 0,09 & 0,32 & 0,05 \\
\hline $\begin{array}{c}\text { Elimination rate } \\
\text { (\%) }\end{array}$ & $\varnothing$ & 21,26 & 13,86 & 9,44 & $-1,17$ & $-140,79$ & 47,69 \\
\cline { 2 - 8 } & $\mathbf{s}$ & 24,53 & 9,15 & 8,17 & 1,06 & 209,62 & 15,78 \\
\hline COD $_{\text {elim./TNelim. }}$ & \multicolumn{7}{|c|}{$\varnothing=5,04$} \\
\hline
\end{tabular}

disturbance of the wastewater treatment plant the nitrification in the plant came to a complete standstill at times.

As a basis for investigations with the addition of external carbon, a test series without carbon addition was run. This investigation was carried out at midsummer temperatures. The COD/TN ratio in the effluent of the secondary treatment was on average 3.0. The mean concentrations and standard deviations in the inflow and outflow as well as the elimination rates for the main parameters are summarised in Table 6.11 .

The results according to Table 6.11 were obtained at very moderate inflow values, so that under such conditions the current requirements for sewage plant effluents in the Tai Lake area could be met. However, this does not apply to the very low total nitrogen value of $6 \mathrm{mg} / \mathrm{L}$ which is aimed for in the future.

The pilot filter tests with the addition of sodium acetate as an external carbon source were carried out in April 2018 at low temperatures and in July/August 2018 at summer temperatures. Table 6.12 lists the conditions for these test phases.

Table 6.12 Process conditions for the pilot filter trials with addition of sodium acetate

\begin{tabular}{|l|c|c|c|c|c|}
\hline \multicolumn{2}{|l|}{ Parameters $(\mathbf{n}=\mathbf{2 7})$} & Min & Max & $\varnothing$ & s \\
\hline pH value & {$[-]$} & 6,35 & 6,81 & 6,53 & 0,16 \\
\hline Redox potential & {$[\mathrm{mV}]$} & 42,17 & 228,97 & 130,76 & 53,27 \\
\hline Oxygen content & {$[\mathrm{ppm}]$} & 0,08 & 1,1 & 0,47 & 0,39 \\
\hline Conductivity & {$[\mu \mathrm{S} / \mathrm{cm}]$} & 1.062 & 1.491 & $1.292,1$ & 137,79 \\
\hline Water temperature & {$\left[{ }^{\circ} \mathrm{C}\right]$} & 19,84 & 29,53 & 26,45 & 3,88 \\
\hline Air temperature & {$\left[{ }^{\circ} \mathrm{C}\right]$} & 8 & 37 & 27 & 6,31 \\
\hline COD/TN ratio & {$[-]$} & 3,1 & 13,1 & 7,34 & 2,53 \\
\hline COD filter bed load & {$\left[\mathrm{kg} /\left(\mathrm{m}^{3} \cdot \mathrm{d}\right)\right]$} & 0,38 & 2,23 & 1,11 & 0,49 \\
\hline TN filter bed load & {$\left[\mathrm{kg} /\left(\mathrm{m}^{3} \cdot \mathrm{d}\right)\right]$} & 0,06 & 0,36 & 0,18 & 0,09 \\
\hline NO3-N filter bed load & {$\left[\mathrm{kg} /\left(\mathrm{m}^{3} \cdot \mathrm{d}\right)\right]$} & 0,02 & 0,25 & 0,11 & 0,07 \\
\hline
\end{tabular}




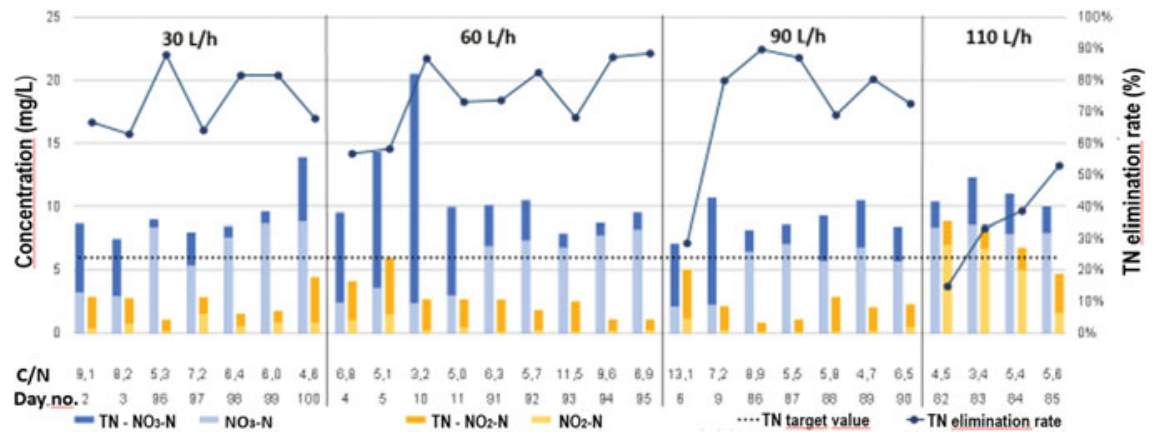

Fig. 6.10 Nitrogen values in the influent and effluent of the pilot filter and $\mathrm{C} / \mathrm{N}$ values and $\mathrm{TN}$ elimination rate for test period with addition of sodium acetate

In April 2018, high nitrite contents of the total nitrogen were present in the effluent from the secondary clarification, while the higher temperatures in summer 2018 led to improved nitrate formation. Figure 6.10 summarizes the results of the test series with carbon addition. The blue bars represent the influent values and the beige bars the effluent values.

Figure 6.10 also shows the different feed rates of the filter system. Even with very high total nitrogen values and a feed rate of up to $90 \mathrm{~L} / \mathrm{h}$, the target effluent value of $6 \mathrm{mg} / \mathrm{L}$ could be maintained. This was no longer possible consistently at the feed rate of $110 \mathrm{~L} / \mathrm{h}$. However, such a high charging rate allows the effluent value of $10 \mathrm{mg} / \mathrm{L}$, which will apply to the Tai Lake area from 2021, to be maintained.

In the investigations on downstream denitrification, compliance with the required or desired COD effluent values was of particular interest. Figure 6.11 shows the COD influent and effluent values according to the nitrogen values shown in Fig. 6.10. The beige bars represent the influent values and the grey bars the effluent values.

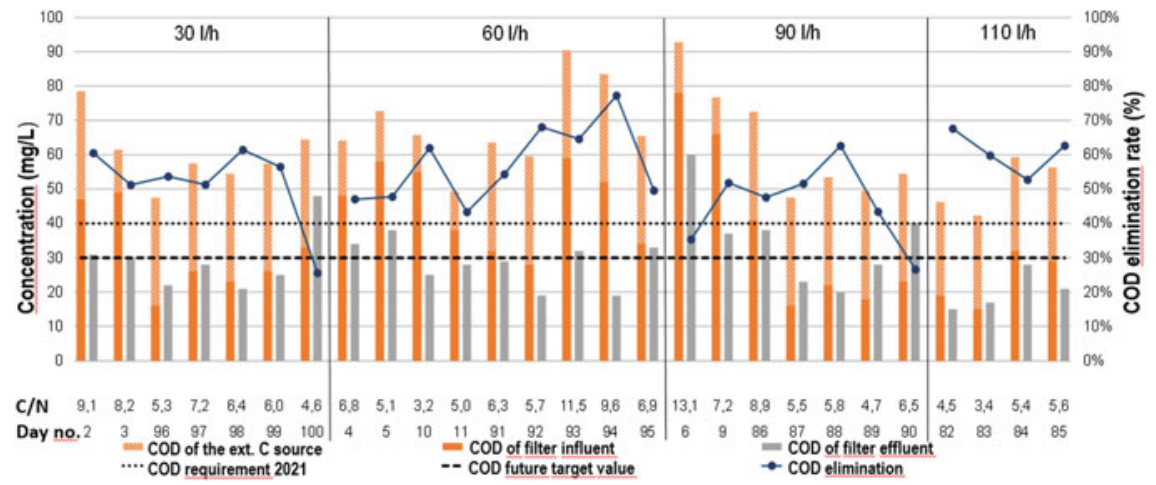

Fig. 6.11 COD values in the influent and effluent of the pilot filter, $\mathrm{C} / \mathrm{N}$ values and $\mathrm{COD}$ elimination rate for test period with addition of sodium acetate 
Only two of the COD effluent concentrations recorded were above the limit of $40 \mathrm{mg} / \mathrm{L}$ applicable to the Tai lake area from 2021, but $40 \%$ of the recorded one above the long-term target of $30 \mathrm{mg} / \mathrm{L}$. The main reason for these exceedances is the high non-degradable or poorly degradable COD content in the secondary treatment effluent, which is not uncommon for industrial wastewater. A future permanent compliance with COD discharge values not exceeding $30 \mathrm{mg} / \mathrm{L}$ will require improved monitoring of industrial discharges with high shear-degradable COD concentrations. Indeed, the results shown in Fig. 6.11 make it clear that the high COD effluent values of the secondary treatment were responsible for the insufficient COD effluent values of the filter and not the carbon added externally before the filtration stage.

Because the elimination rates for COD and total nitrogen were relatively low in the first week of the experiments with carbon addition with increased feeding of the pilot filter, it was decided to carry out a series of experiments with additional nitrate addition. The discharge and inflow values as well as the elimination rates for nitrogen are shown in Fig. 6.12. The blue bars represent the influent values and the beige bars the effluent values.

The outside temperatures during this series of tests averaged $24{ }^{\circ} \mathrm{C}$. Even with the addition of sodium nitrate, relatively low influent concentrations for the total nitrogen were obtained. According to Fig. 6.12, the effluent values were clearly below the future target total nitrogen value of $6 \mathrm{mg} / \mathrm{L}$ even at a feed rate of $90 \mathrm{~L} / \mathrm{h}$.

The influent and effluent values for COD and COD elimination are shown in Fig. 6.13. The beige bars represent the influent values and the grey bars the effluent values.

On all days of the study, the COD effluent value of $40 \mathrm{mg} / \mathrm{L}$, which will apply from 2021 for wastewater treatment plants in the Tai Lake area, was maintained regardless of the filter feed and despite the carbon dosage. With the exception of one day, this also applied to the future target value of $30 \mathrm{mg} / \mathrm{L}$.

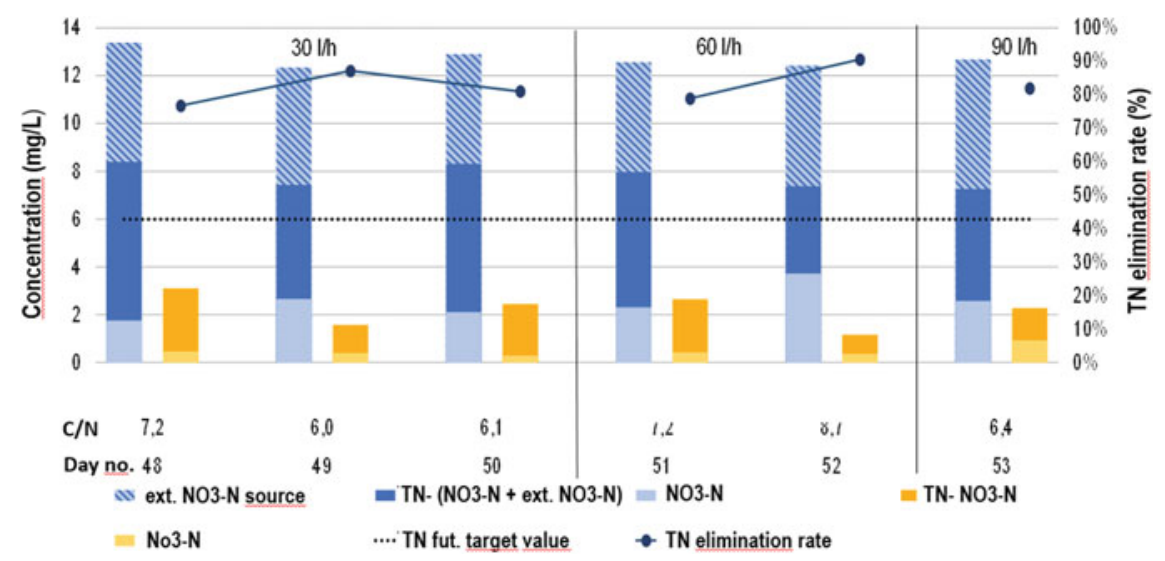

Fig. 6.12 Influent and effluent concentrations for TN and NO3-N and TN elimination rate for test period with addition of external carbon and nitrate 


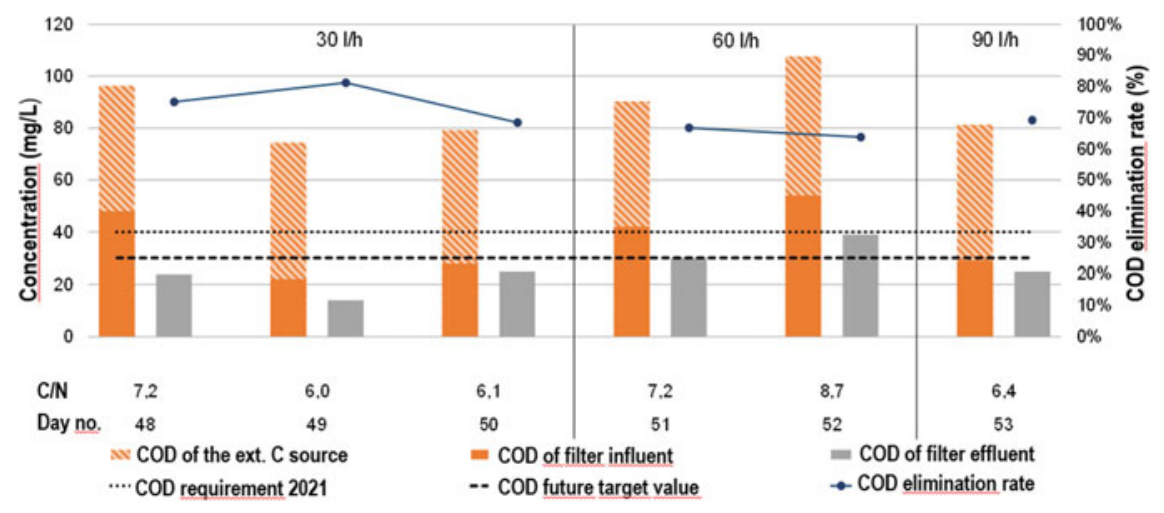

Fig. 6.13 COD values in the influent and effluent of the pilot filter, $\mathrm{C} / \mathrm{N}$ values and COD elimination rate for test period with addition of sodium acetate and nitrate

The results of all investigations with the anoxic pilot filter system can be summarized as The results of all investigations with the anoxic pilot filter system can be summarised as follows:

The purpose of the pilot tests was to improve the nitrogen elimination taking place in the biological treatment stage down to very low total nitrogen concentrations. As the COD in the effluent of the final clarification was, as expected, only available to a small extent as a substrate for denitrification, the addition of an external carbon substrate proved to be very effective. Very low total nitrogen values could be achieved, so that the future target value of $6 \mathrm{mg} / \mathrm{L}$ at most would have to be met. However, the prerequisite for such performance of the downstream denitrification stage is a functioning nitrification in the upstream biological treatment stage. The massive disturbance of the wastewater treatment plant during the test period, presumably caused by toxic substances in the industrial wastewater, led to an extensive prevention of nitrification. Reliable online monitoring and technical measures in the indirect discharger area or at the Suzhou II treatment plant must prevent such disturbances if permanent and extensive nitrogen elimination is to be guaranteed in future.

Compliance with future COD requirements in the effluent of the treatment plant will not depend on the addition of an external carbon source. Given the existing process engineering situation of the wastewater treatment plant, it is necessary that the inert COD content in the effluent of the secondary clarification will in future be below the required COD effluent values of 40 or $30 \mathrm{mg} / \mathrm{L}$. If this cannot be achieved due to the industrial wastewater treated in the treatment plant, a specific elimination stage for the hardly degradable organic wastewater constituents would have to be provided. 


\subsubsection{Sludge Water Treatment}

As mentioned in Sect. 6.4, investigations were also carried out at the Suzhou WWTP using pilot plants for nitrogen elimination from the sludge water substream. The aim is not to improve the elimination performance by treatment in the main wastewater treatment stream, but in the sludge treatment substream. In Germany, corresponding process engineering solutions have already proven themselves on a large scale.

\section{Operation of an SBR-MBBR Experimental Plant}

The investigations were carried out in the summer months of 2018 and were carried out by the German company EvU. The core of the plant was a Moving Bed Biofilm Reactor (MBBR), which was operated as a sequencing batch reactor. The test plant, which is located in a container at the Suzhou II wastewater treatment plant, is shown in Fig. 6.14. It consisted of a storage tank, an SBR reactor and an outlet tank for sampling as well as a switchgear for control. The reactor had a diameter of $30 \mathrm{~cm}$ and a height of $51 \mathrm{~cm}$ corresponding to a volume of $36 \mathrm{~L}$. EvU-Pearl® plastic bodies with a specific surface of $700 \mathrm{~m}^{2} / \mathrm{m}^{3}$ served as carrier material. The $10.8 \mathrm{~L}$ of material used corresponded to a filling ratio of $30 \%$.

The MBBR plant was fed with the process water of the mechanical sludge dewatering of the sewage treatment plant in order to determine its biodegradability with regard to nitrogen and COD.

The storage tank was used to store the wastewater to be treated. The wastewater was treated in batches according to a specified cycle. By switching off the aeration the cleaning process of the pre-cycle was finished and the sedimentation phase was initiated. The sedimenting carrier material EvU®-Pearl settled at the bottom of the SBR. Above the sedimentation layer a clear phase with purified waste water formed. The sedimentation phase was followed by the withdrawal phase. Excess sludge was

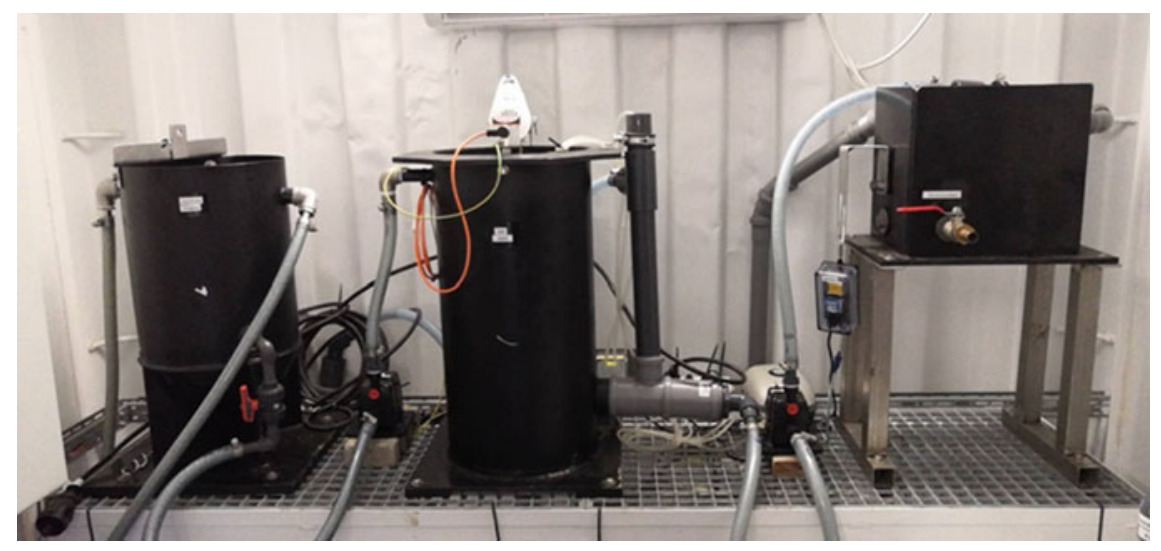

Fig. 6.14 MBBR pilot plant at Suzhou II wastewater treatment plant for sludge water treatment 
Table 6.13 Cycle settings during the entire operating period of the MBBR pilot plant

\begin{tabular}{|l|c|c|c|c|c|c|c|c|}
\hline Versuchsphasen & $\mathrm{I}$ & $\mathrm{II}$ & $\mathrm{III}$ & $\mathrm{IV}$ & $\mathrm{V}$ & $\mathrm{VI}$ & $\mathrm{VII}$ & $\mathrm{VIII}$ \\
\hline Phasen/Zeit(s) & $\mathrm{ab}$ & $\mathrm{ab}$ & $\mathrm{ab}$ & $\mathrm{ab}$ & $\mathrm{ab}$ & $\mathrm{ab}$ & $\mathrm{ab}$ & $\mathrm{ab}$ \\
& 04.06 & 22.06 & 16.07 & 24.07 & 30.07 & 10.08 & 27.08 & 27.09 \\
\hline Füllen & 60 & 60 & 60 & 60 & 60 & 60 & 60 & 60 \\
\hline Stillstand & 100 & 100 & 100 & 100 & 100 & 100 & 100 & 0 \\
\hline Mischen & 500 & 800 & 1160 & 520 & 1640 & 1730 & 1630 & 1515 \\
\hline Beluften & 1200 & 900 & 540 & 780 & 1090 & 1200 & 1200 & 1515 \\
\hline Sedimentieren & 3180 & 3180 & 3180 & 1980 & 4200 & 3000 & 3600 & 3000 \\
\hline Abzug & 60 & 60 & 60 & 60 & 60 & 60 & 60 & 60 \\
\hline Gesamtzyklus & 14400 & 14400 & 14400 & 10800 & 21600 & 21600 & 21600 & 21600 \\
\hline
\end{tabular}

removed at specified intervals and fed into a sludge storage tank. Four to eight cycles were run daily.

After a two-week running-in phase, eight test phases were carried out in the investigation period from June to September 2018. Table 6.13 shows the test periods and the SBR cycles for these test phases.

Due to low denitrification performance in the initial test phases, the dosing of an external one was later carried out according to the following schedule.

\begin{tabular}{|l|l|l|l|l|l|l|}
\hline $\begin{array}{l}\text { CSB-Zugabe } \\
\text { (mg/L): }\end{array}$ & ab 09.07. & ab 06.08. & ab 20.08. & ab 27.08. & ab 03.09. & ab 12.09. \\
\cline { 2 - 7 } & 100 & 150 & 160 & 170 & 180 & 190 \\
\hline
\end{tabular}

The investigations concentrated on nitrification and especially on nitrogen elimination. Of course, the influence of the feeding cycles was also of importance. Figure 6.15 shows the inlet and outlet concentrations of ammonium nitrogen and the corresponding elimination rates during the eight investigation phases applied. It should be noted that the concentrations of ammonium nitrogen in the sludge water in Germany are several times higher than the concentrations shown in Fig. 6.15 and range between 30 and $50 \mathrm{mg} / \mathrm{L}$.

In the middle of phase I and VII, good NH4-N oxidation was temporarily achieved at an aeration ratio of $67 \% / 33 \%$. As expected, the elimination performance decreased with reduction of the aeration time. In total, more than $50 \%$ of the ammonium could be oxidized continuously.

Nitrogen elimination was very low in the first four test phases, as can be seen from Fig. 6.16. The reason for this was the relatively low COD with values between 50 and $200 \mathrm{mg} / \mathrm{L}$, most of which is not available for the necessary denitrification. This changed with increased addition of external carbon. 


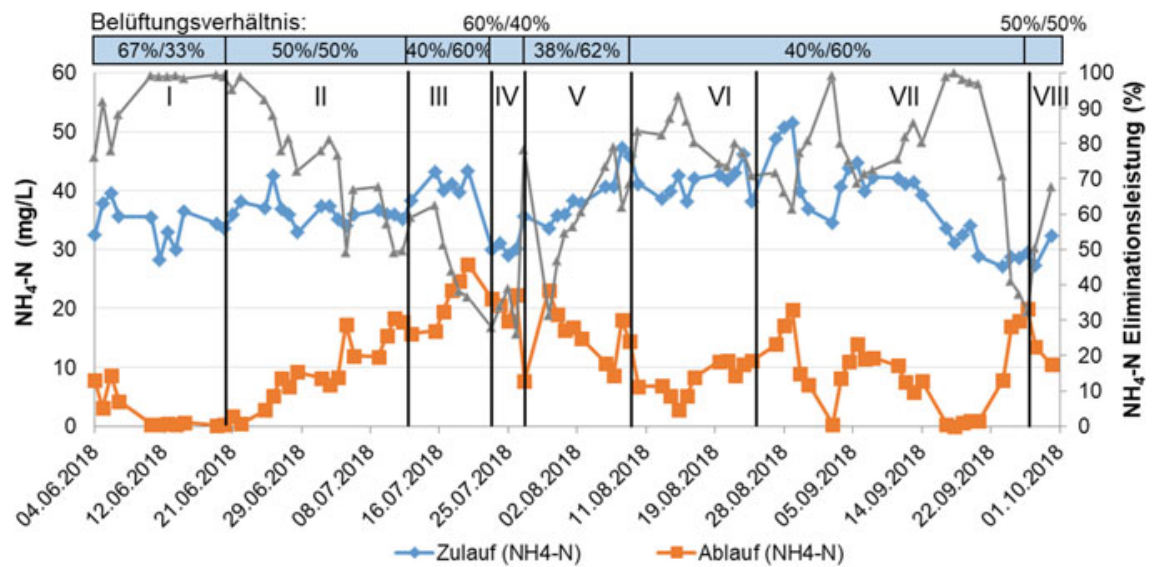

Fig. 6.15 Inflow and effluent concentrations of NH4-N and elimination performance as a function of cycle setting and aeration ratio during the investigations with the MBBR pilot plant

\section{Kohlenstgffzugabe (mg $\mathrm{COD} / \mathrm{L})$ :}

\begin{tabular}{|l|l|l|l|l|l|}
100 & 150 & 160 & 170 & 180 & 190 \\
\hline
\end{tabular}
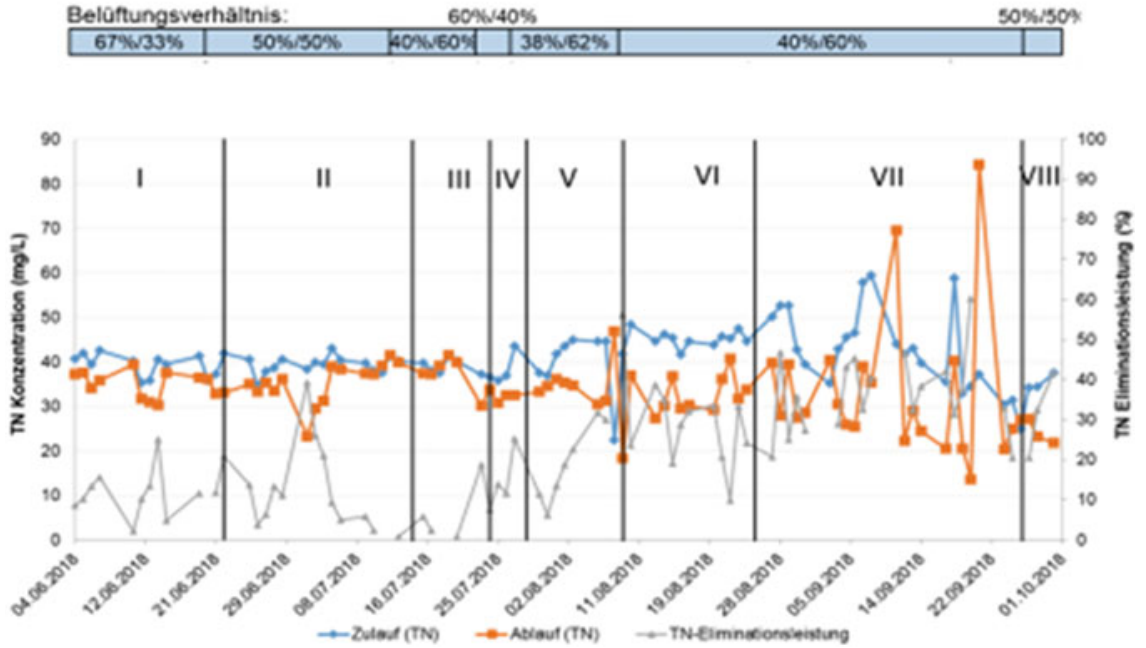

Fig. 6.16 Inflow and effluent concentrations of total nitrogen $\mathrm{TN}$ and elimination rates during the investigations with the MBBR pilot plant

Figure 6.16 shows the inflow and outflow values for total nitrogen and the corresponding elimination performance. The respective aeration ratio and the addition of carbon were also indicated. The moderate elimination rates for the nitrogen are also clear from this picture. 
Investigations on the correlation between the ammonia nitrogen surface load of the carrier bodies and the surface oxidation performance showed that surface loads between 4.5 and $6 \mathrm{~g} / \mathrm{m}^{2} * \mathrm{~d}$ led to good performances. These values could be used as a basis for plant dimensioning in the event of a possible large-scale technical application.

In summary, the tests carried out confirmed that the nitrogen loads present in the process water of mechanical sludge dewatering can be reduced by means of the MBBR process. Thus the main biological load can be reduced accordingly. However, it appears questionable whether such a bypass treatment stage is economically viable at the low ammonia nitrogen concentrations and COD values, since an acceptable nitrogen elimination performance can only be achieved with the aid of an external carbon source.

Due to the low ammonium concentrations of the sludge water, the investigations also did not include the installation of a magnesium-ammonium-phosphate separation (MAP stage). Such a process engineering solution could otherwise have been installed in the feed tank of the test plant and would have ensured a desirable removal of ammonium from the sludge water.

\section{Operation of a Pilot Plant for Deammonification}

The sludge water resulting from the dewatering of digested sludge is highly nitrogenous and is usually returned to the biological wastewater treatment plant. This means an additional load of about 10 to $15 \%$ of the nitrogen input load and makes a separate treatment of the sludge water appear sensible because the process stability of nitrogen elimination can be significantly improved. In recent years, so-called deammonification has proved to be an effective method of such a bypass treatment. Deammonification in particular, with its high energy and cost saving potential, has currently led to an increased number of partial flow plants being built in practice. At present, approx. 70 plants for the treatment of sludge water in partial flow are operated in Germany.

In the process of deammonification, about half of the ammonium contained in the sludge water is first converted to nitrite under aerobic conditions, which is then converted to gaseous nitrogen and about $10 \%$ nitrate under anaerobic conditions with the help of specialized bacteria (planktomycetes) together with the other half of the ammonium. Figure 6.17 shows the basic principles of conventional nitrification/denitrification and deammonification (Lackner et al. 2013).

Compared to the classic nitrification/denitrification, the ammonia ionization process uses $60 \%$ less oxygen and $100 \%$ less carbon. Furthermore, due to the slow growth rates of the microorganisms involved, considerably less excess sludge is produced.

To demonstrate deammonification in China, a laboratory test plant was operated at the Suzhou II wastewater treatment plant in 2018. The German company ATEMIS, which has extensive practical experience in deammonification, was responsible for this. The sewage treatment plant was suitable for the investigations because it has a sewage sludge digestion system and a similarly high amonium nitrogen load in the sludge water as in Germany was expected. It turned out that for the investigations 


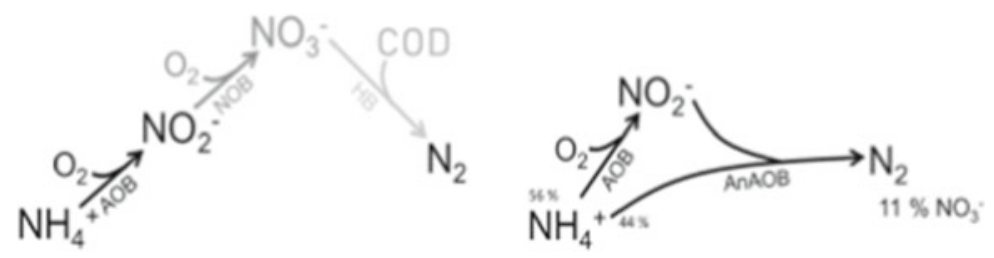

Fig. 6.17 Comparison of conventional nitrogen elimination and deammonification of wastewater

an increase by external ammonium nitrogen was necessary due to the very low contamination of the sludge water on site.

The functionality of the experimental plant could not be fully exploited because the very specific sludge required for nitritation was not available in sufficient quantity. Since such a sludge did not exist in China up to now, a transport of corresponding quantities of inoculated sludge from Germany was planned for the start-up of the pilot plant. In order to avoid difficulties during a long lasting transport in shipping containers or air freight, a freeze drying of suitable inoculation sludge was carried out in Germany and the sludge was taken to China as hand luggage. This measure was basically successful, as the dried inoculation sludge could be revived in the test plant. However, due to the limited drying capacity, the amount of sludge and the bacterial mass was too small for full-load operation of the test plant.

For economic reasons, the deammonification of nitrogen-contaminated sludge water will only be feasible in China if the nitrogen potential to be oxidized is at least $100 \mathrm{mg}$ NH4-N. In any case, preliminary practical tests should be carried out.

\subsection{Recommendations for Future Wastewater Treatment in the Investigated Wastewater Treatment Plant}

The background to the investigations carried out at the Suzhou II wastewater treatment plant in 2017 and 2018 was the finding that improved treatment performance of the plant appears necessary to meet future requirements. The following recommendations for the future design and operation of the plant can be derived from the investigations.

The operation of wastewater treatment plants with a high proportion of industrial wastewater requires precise knowledge of the industrial wastewater to be treated. This also includes immediate information in case of operational disturbances or changes in production in the industrial wastewater producing companies, if these have an impact on the wastewater quality. The operator of the wastewater treatment plant under investigation did not have any complete information on this subject until now. It is recommended to establish a regularly updated cadastre for the industrial companies 
connected to the treatment plant, including all relevant wastewater data including the wastewater pretreatment plants. With regard to operational pre-treatment measures, the competent supervisory authority should clarify whether a targeted partial flow treatment of particularly polluted wastewater should be carried out instead of pretreating the entire operational wastewater.

In future, compliance with very low nitrogen levels will mean targeted measures for the Suzhou II treatment plant. One possibility is the dosing of external carbon for denitrification in the biological treatment stage. For economic reasons and sustainability, it is recommended that suitable organic residues from operations in the Suzhou Industrial Park be used. However, their suitability and effect would have to be investigated in the laboratory before their large-scale use.

In view of the necessity to maintain very low effluent values for nitrogen in the future, the use of a denitrification in an anoxic filter plant downstream of the biological treatment stage seems very sensible. Due to the low availability of COD in the effluent of the final clarification to ensure nitrate respiration in the filter plant, the addition of an external carbon substrate will become necessary. To adapt to the purification requirements for compliance with the requirements, it may make sense for economic reasons to lead only a partial flow of the secondary clarification effluent through the filter plant, at least temporarily.

In order to meet the requirements of the COD effluent values of the treatment plant, it will be necessary in the future that the inert COD content in the final sedimentation effluent is below the required COD effluent values of $40 \mathrm{mg} / \mathrm{L}$ or $30 \mathrm{mg} / \mathrm{L}$. If this cannot be achieved due to the industrial waste water treated in the treatment plant, a specific elimination stage must be provided for the hardly degradable organic waste water constituents. For this purpose, either adsorption with activated carbon or chemical oxidation is suitable.

\subsection{Summary}

The special importance of Lake Tai for the water supply in the Shanghai area has led to very demanding new requirements for wastewater treatment in the catchment area of the lake, due to the high levels of pollution, especially of plant nutrients, that have been known for years. Within the scope of German research activities belonging to the Chinese Mayor Water Programme, a contact was established with the Chinese company Huayan Water Affairs Co., Ltd., which is responsible for the water supply and wastewater disposal in the Suzhou Industrial Park on Lake Tai. This resulted in a research project financed by the German Ministry of Education and Research (BMBF) and the company Huayan Water. Using the example of the Suzhou Sewage Treatment Plant II in the Industrial Park Suzhou, which has to treat a considerable proportion of industrial wastewater, approaches for the future improvement of wastewater treatment were to be investigated on the basis of German experience. 
The focus was on extreme demands on the wastewater treatment plant effluent with $6 \mathrm{mg} / \mathrm{L}$ total nitrogen and $30 \mathrm{mg} / \mathrm{L}$ COD.

The investigations carried out covered both technological and management aspects. For the future successful function of the investigated wastewater treatment plant it seems to be important that all basic and current data and information about the different wastewaters of the connected industrial plants are available during the treatment operation.

Investigations in the laboratory of the sewage treatment plant and with the help of three pilot plants in operation resulted in various findings. This has resulted in the following suggestions and notes, among others.

- It seems worth considering whether in future the sedimentation plant upstream of the biological treatment stage should continue to be used as such or whether it should be used for other purposes.

- For the dosing of an external carbon source that will be necessary in the future to improve nitrogen elimination, suitable organic substrates from the Suzhou Industrial Park should be used as industrial residues instead of conventional products.

- For the stability of a future very extensive denitrification the arrangement of an anoxic filtration plant downstream of the biological clarification stage with dosing of external carbon seems to be reasonable.

- If, in future, it will not be possible to permanently reduce the COD that is difficult to degrade during the final clarification process, an additional procedural measure will be necessary. Either activated carbon adsorption or chemical oxidation can be considered for this purpose.

In conclusion, it should be noted that the research project carried out resulted in a very trustful and harmonious cooperation between all Chinese and German partners involved.

\section{References}

Amed J, Bumiller W, Kusche I, Donnert D (2000) Effiziente Abwasserreinigung durch einfache Prozessmodifikation und Nutzung von Küchenabfällen, Forschungszentrum Karlsruhe Technik und Umwelt, Karlsruhe

ABWV (2004) Verordnung über Anforderungen an das Einleiten von Abwasser in Gewässer Abwasserverordnung - AbwV, 17.06.2004 (BGB1. I S. 1109, S. 2625)

Dohmann M (2014) Combined or separate treatment of municipal and industrial wastewater, Presentation on 11 October 2012 at the Chin Research Acad of Envir Sciences in Beijing

DWA (2013) DWA Merkblatt M 115-1 und -2 Indirekteinleitung nicht häuslichen Abwassers, Hennef

Görner K, Hübner K (1999) Umweltschutztechnik, Springer Verlag, Berlin

Lackner S, Horn H, Schreff D (2013) Pilotvorhaben Deammonifikation, DVGW, Karlsruhe

Lee V (2018) Advanced post-treatment nitrogen elimination using an anoxic biofilter on the example of a Chinese industrial wastewater treatment plant, Master thesis at the RWTH Aachen University, Aachen, Sept. 2018 
Xiang L (2017) Treatment technology of pharmaceutical wastewater, SINOWATER Workshop, September 8, 2017, Bejing

Xu Y (2016) 8 Things about recycling water, China Water Risk, October 19, 2016

Open Access This chapter is licensed under the terms of the Creative Commons Attribution 4.0 International License (http://creativecommons.org/licenses/by/4.0/), which permits use, sharing, adaptation, distribution and reproduction in any medium or format, as long as you give appropriate credit to the original author(s) and the source, provide a link to the Creative Commons license and indicate if changes were made.

The images or other third party material in this chapter are included in the chapter's Creative Commons license, unless indicated otherwise in a credit line to the material. If material is not included in the chapter's Creative Commons license and your intended use is not permitted by statutory regulation or exceeds the permitted use, you will need to obtain permission directly from the copyright holder.

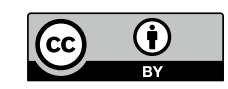

